\title{
Facilitation of colonic T cell immune responses is associated with an exacerbation of dextran sodium sulfate- induced colitis in mice lacking microsomal prostaglandin E synthase-1
}

Fumiaki Kojima ${ }^{1,2,3^{*}}$ (D), Hiroki Sekiya ${ }^{2}$, Yuka Hioki $^{1}$, Hitoshi Kashiwagi ${ }^{4}$, Makoto Kubo ${ }^{3,5}$, Masaki Nakamura ${ }^{3,6}$, Shotaro Maehana ${ }^{3,6}$, Yoshitaka Imamichi ${ }^{4}$, Koh-ichi Yuhki ${ }^{4}$, Fumitaka Ushikubi ${ }^{4}$, Hidero Kitasato ${ }^{3,6}$ and Takafumi Ichikawa ${ }^{2,3}$

\begin{abstract}
Background: Microsomal prostaglandin E synthase-1 (mPGES-1) is a key enzyme that acts downstream of cyclooxygenase and plays a major role in inflammation by converting prostaglandin ( $P G) \mathrm{H}_{2}$ to $P G E_{2}$. The present study investigated the effect of genetic deletion of mPGES-1 on the development of immunologic responses to experimental colitis induced by dextran sodium sulfate (DSS), a well-established model of inflammatory bowel disease (IBD).

Methods: Colitis was induced in mice lacking mPGES-1 (mPGES-1 ${ }^{-1-}$ mice) and wild-type (WT) mice by administering DSS for 7 days. Colitis was assessed by body weight loss, diarrhea, fecal bleeding, and histological features. The colonic expression of mPGES-1 was determined by real-time PCR, western blotting, and immunohistochemistry. The impact of MPGES-1 deficiency on T cell immunity was determined by flow cytometry and $T$ cell depletion in vivo.
\end{abstract}

\footnotetext{
* Correspondence: kojimaf@kitasato-u.ac.jp

${ }^{1}$ Department of Pharmacology, Kitasato University School of Allied Health

Sciences, 1-15-1 Kitasato, Sagamihara 252-0373, Japan

${ }^{2}$ Department of Regulation Biochemistry, Kitasato University Graduate School

of Medical Sciences, 1-15-1 Kitasato, Sagamihara 252-0373, Japan

Full list of author information is available at the end of the article
}

(C) The Author(s). 2022 Open Access This article is licensed under a Creative Commons Attribution 4.0 International License, which permits use, sharing, adaptation, distribution and reproduction in any medium or format, as long as you give appropriate credit to the original author(s) and the source, provide a link to the Creative Commons licence, and indicate if changes were made. The images or other third party material in this article are included in the article's Creative Commons licence, unless indicated otherwise in a credit line to the material. If material is not included in the article's Creative Commons licence and your intended use is not permitted by statutory regulation or exceeds the permitted use, you will need to obtain permission directly from the copyright holder. To view a copy of this licence, visit http://creativecommons.org/licenses/by/4.0/. 
Results: After administration of DSS, mPGES-1 ${ }^{-/}$mice exhibited more severe weight loss, diarrhea, and fecal bleeding than WT mice. Histological analysis further showed significant exacerbation of colonic inflammation in mPGES-1 $1^{-1-}$ mice. In WT mice, the colonic expression of mPGES-1 was highly induced on both mRNA and protein

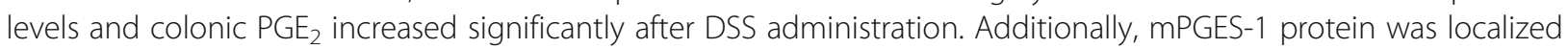
in the colonic mucosal epithelium and infiltrated inflammatory cells in underlying connective tissues and the lamina propria. The abnormalities consistent with colitis in $\mathrm{mPGES}-1^{-1-}$ mice were associated with higher expression of colonic T-helper (Th)17 and Th1 cytokines, including interleukin 17A and interferon- $\gamma$. Furthermore, lack of mPGES-1 increased the numbers of Th17 and Th1 cells in the lamina propria mononuclear cells within the colon, even though the number of suppressive regulatory $T$ cells also increased. CD4 ${ }^{+} T$ cell depletion effectively reduced symptoms of colitis as well as colonic expression of Th17 and Th1 cytokines in mPGES-1 ${ }^{-/-}$mice, suggesting the requirement of $\mathrm{CD}^{+}{ }^{+} \mathrm{T}$ cells in the exacerbation of DSS-induced colitis under MPGES-1 deficiency.

Conclusions: These results demonstrate that mPGES-1 is the main enzyme responsible for colonic PGE 2 production and deficiency of mPGES-1 facilitates the development of colitis by affecting the development of colonic T cellmediated immunity. mPGES-1 might therefore impact both the intestinal inflammation and T cell-mediated immunity associated with IBD.

Keywords: Inflammatory bowel disease, Colitis, Immunity, Th17 and Th1 response, Cytokine, Cyclooxygenase, Prostaglandin E synthase, Prostaglandin $\mathrm{E}_{2}$

\section{Introduction}

Inflammatory bowel disease (IBD), which includes ulcerative colitis and Crohn's disease, is a chronic inflammatory disease that is accompanied by abnormalities in the immune system. Although the etiology and pathogenesis of IBD remain largely unknown, multiple risk factors, such as environmental triggers, genetic susceptibility, and alteration of gut microbial flora, have been implicated in its initiation or progression $[1,2]$. T cells, which in the presence of various cytokines differentiate into different types of T-helper (Th) cells, including Th1, Th2, Th17, and regulatory $\mathrm{T}$ cells (Tregs), are widely accepted to play a major role in the pathogenesis of IBD [3]. An altered Th cytokine network, along with excessive abnormal immune responses, is closely linked to the development of IBD. Biological therapies have been developed with monoclonal antibodies that target Th1 and Th17 cytokines produced by effector $\mathrm{T}$ cells, and some of these therapies have proven to be clinically useful for treating patients with IBD and several autoimmune diseases [4].

Prostaglandin (PG) $E_{2}$ is a lipid mediator of many physiological and pathological functions whose production is regulated by the sequential enzymatic pathway involving cyclooxygenase (COX) and PGE synthase (PGES) $[5,6]$. On the basis of early studies, COX activity-consisting of constitutive COX-1 and inducible COX-2-had been considered the key step in $\mathrm{PGE}_{2}$ synthesis, but subsequent studies discovered that at least three distinct PGES isozymes, cytosolic PGES (cPGES), and microsomal PGES-1 (mPGES-1) and mPGES-2, are responsible for the final step of $\mathrm{PGE}_{2}$ synthesis downstream from COX [7-10]. $\mathrm{PGE}_{2}$ is known to be a major mediator in gastrointestinal homeostasis and also to be highly produced in the inflamed mucosa of patients with IBD [11]. It is well known to act through 4 kinds of receptor subtypes, $\mathrm{EP}_{1}, \mathrm{EP}_{2}, \mathrm{EP}_{3}$, and $\mathrm{EP}_{4}$, which mediate different signaling [12]. Among the EP receptor subtypes, $\mathrm{EP}_{4}$ plays a pivotal role in regulating pathological events in IBD, as well as in maintaining gastrointestinal homeostasis [13-15]. An evaluation of biopsies from patients with IBD showed that both COX-2 expression and $\mathrm{PGE}_{2}$ production increase during active phases of the disease [16]. Accordingly, several studies and case reports have implicated nonsteroidal anti-inflammatory drugs (NSAIDs), which inhibit COX activity, in the onset or exacerbation of IBD [17].

One type of PGES, mPGES-1, is an inducible enzyme that acts downstream of COX and specifically catalyzes the conversion of $\mathrm{PGH}_{2}$ to $\mathrm{PGE}_{2}[7,8]$. Several studies in mice lacking $\mathrm{mPGES}-1$ (mPGES-1 ${ }^{-1-}$ mice) have provided novel findings on the role of mPGES-1 as a key mediator of many physiological and pathophysiological events in a number of different disease states associated with inflammation and immune response [18-24]. We have previously reported that resistance to bovine type II collagen-induced arthritis in mPGES-1 ${ }^{-/-}$mice is associated with a failure to develop type II collagen-specific antibodies, suggesting an important role of mPGES-1 and its driven $\mathrm{PGE}_{2}$ in the development of acquired immune response [25]. We also reported that mPGES1-driven $\mathrm{PGE}_{2}$ facilitates $\mathrm{T}$ cell-dependent, antigenspecific humoral responses [26] and also promotes expansion of antigen-specific Th17 and Th1 responses 
in an autocrine and paracrine fashion [27]. These previous findings strongly suggested the pivotal roles of mPGES-1 in pathogenic T cell immunity.

mPGES-1 protein is overexpressed in inflamed intestinal mucosa of patients with IBD including ulcerative colitis and Crohn's disease, and mPGES-1 transcription is induced in vitro in human colonocytes in response to stimulation with TNF $\alpha$, a major cytokine implicated in intestinal inflammation in IBD [28], suggesting the importance of mPGES-1 in the pathogenesis of IBD. However, the role of overexpressed mPGES-1 in IBD is still largely unknown.

A dextran sodium sulfate (DSS)-induced colitis model, which is highly dependent on both humoral and cellular immunity, is widely used as a well-established model of IBD [29]. Previous studies have shown that mPGES-1 ${ }^{-/-}$ mice are highly susceptible to DSS-induced colitis [30, 31], but the detailed intrinsic mechanisms underlying their susceptibility have not been fully elucidated. The present study demonstrates that mPGES- 1 is the main enzyme responsible for colonic $\mathrm{PGE}_{2}$ production and exerts anti-colitis activities associated with the suppression of Th17 and Th1 immunologic responses in DSSinduced colitis. Conversely, we also indicate the possible potential for mPGES-1 as a pathogenic factor of colitis by regulating Tregs. Furthermore, our study using $\mathrm{T}$ cell depletion suggests the anti-colitis effect of mPGES-1 related to the $\mathrm{T}$ cells. Our findings suggest that mPGES1-driven $\mathrm{PGE}_{2}$ has a significant impact on not only the intestinal inflammation but also the pathogenic $\mathrm{T}$ cell immunity associated with IBD.

\section{Materials and methods \\ Mice}

mPGES-1 ${ }^{-1-}$ mice with a C57BL/6 background, originally generated by Prof. Shizuo Akira [22], were purchased from the Oriental Bioservice Inc. (Kyoto, Japan). mPGES-1 heterogeneous mice were mated to generate mPGES-1 ${ }^{-1-}$ mice and littermate wild-type (WT) mice. Genotypes were identified by polymerase chain reaction (PCR) analysis of a tail biopsy DNA extract by using specific primers for the $\mathrm{mPGES}-1^{-1-}$ allele and WT allele. Mice were housed in cages in a specific pathogen-free barrier facility and were cared for and handled in accordance with the guidelines of the Animal Research and Ethics Committee of Kitasato University and the Safety Committee for Recombinant DNA Experiments of Kitasato University. All animal experiments were approved by the Animal Research and Ethics Committee of Kitasato University (Approval number Ei-ken 19-12), and all experiments in mPGES-1 $1^{-/-}$mice were approved by the Safety Committee for Recombinant DNA Experiments of Kitasato University (Approval number 3593).

\section{Induction of colitis}

This study used female mice aged 8 to 12 weeks old. To induce development of colitis, high-molecular-weight, colitis-grade DSS with an average molecular weight of 36,000 to 50,000 (MP Biomedicals, Santa Ana, CA, USA) was added to the drinking water for 7 days at a concentration of either 1 or $2 \%$ [32]. Control mice were received plain drinking water without DSS. The severity of colitis was assessed daily by scoring body weight loss, stool consistency, and occult blood in the stool on a scale ranging from 0 (normal) to 4 (severe) and calculating the total disease activity index (DAI) score as the sum of these 3 scores (maximum score: 12), in accordance with a previous report [33]. To evaluate anemia, we measured the number of erythrocytes and concentration of hemoglobin (HGB) and hematocrit (HCT) in peripheral blood by Celltac alpha (Nihon Kohden, Tokyo, Japan).

\section{Histological assessment of colitis}

On day 7 after the start of exposure to DSS, mice were euthanized under anesthesia, and the colons and spleens were collected (we used the adapted Swiss roll technique to collect the colons). Samples were fixed in $4 \%$ paraformaldehyde and then embedded in paraffin. Sections of $3.5-\mu \mathrm{m}$ thickness were stained with hematoxylin and eosin (H\&E). Histological analysis of colitis was performed by an observer blinded to the genotypes of the mice. The severity of colitis was rated on the basis of the degree of epithelial damage and inflammatory infiltration. The scores for epithelial damage were as follows: no obvious damage, 0 ; loss of goblet cells, 1 ; loss of crypts in the basal one third of the epithelium, 2; loss of crypts in the basal two thirds of the epithelium, 3; and damage to the entire crypt with an intact surface epithelium, 4.

Inflammatory infiltration was scored as follows: no infiltration, 0 ; infiltration around crypt bases, 1 ; infiltration reaching the muscularis mucosa, 2; extensive infiltration reaching the muscularis mucosa and thickening of the mucosa with abundant edema, 3; and infiltration of the submucosa, 4. The histological score was calculated as the sum of the epithelial damage and inflammatory infiltration scores (maximum score: 8 ), in accordance with previous reports [33, 34].

\section{Epithelial barrier permeability}

Intestinal barrier function was assessed with fluorescein isothiocyanate (FITC)-dextran with an average molecular weight of 3000 to 5000 (FD4; Sigma), according to a previous report [35]. Briefly, mice were deprived of food overnight and then FITC-dextran was administered orally $(10 \mathrm{mg} /$ mouse at a concentration of $25 \mathrm{mg} / \mathrm{mL}$ ). After $4 \mathrm{~h}$, blood was immediately collected by cardiac 
puncture at the time of euthanasia under the anesthesia. The FITC-dextran content in serum was determined by FLUOstar OPTIMA (BGM LABTECH, Offenburg, Germany) with excitation and emission wavelengths of $485 \mathrm{~nm}$ and $520 \mathrm{~nm}$, respectively. Dilutions of FITCdextran were used as a standard curve.

\section{Real-time PCR analysis}

Total RNA was isolated from the colon with a NucleoSpin RNA kit (Macherey-Nagel, Duren, Germany). Firststrand cDNAs were synthesized with SuperScript VILO (Thermo Fisher Scientific, Waltham, MA, USA), and then real-time PCR was performed with a Thunderbird SYBR qPCR Mix (Toyobo, Osaka, Japan) in the ABI 7500 Real-Time PCR System (Thermo Fisher Scientific). The primer sets (Eurofins, Luxembourg City, Luxembourg) used in this study are listed in Table 1. The cycling conditions of the PCR reaction were as follows: $1 \mathrm{~min}$ at $95^{\circ} \mathrm{C}$, followed by 40 cycles of $15 \mathrm{~s}$ each at $95{ }^{\circ} \mathrm{C}$ and $1 \mathrm{~min}$ at $60^{\circ} \mathrm{C}$. The threshold cycle value was normalized by reference to glyceraldehyde 3phosphate dehydrogenase (GAPDH).

\section{Western blot analysis}

The tissues were homogenized and lysed in a buffer containing $40 \mathrm{mmol} / \mathrm{L}$ Tris $/ \mathrm{HCl}(\mathrm{pH} 7.4), 150 \mathrm{mmol} / \mathrm{L}$ $\mathrm{NaCl}, 2 \mathrm{mmol} / \mathrm{L}$ EDTA, $1 \mathrm{mmol} / \mathrm{L}$ dithiothreitol, $1 \%$ Triton X-100, $2 \mathrm{mmol} / \mathrm{L}$ sodium orthovanadate, 10 $\mathrm{mmol} / \mathrm{L} \mathrm{NaF}$, and $10 \mathrm{mmol} / \mathrm{L}$ sodium pyrophosphate supplemented with a protease inhibitor cocktail mixture (Sigma, St Louis, MO, USA). Protein contents were measured by a BCA protein assay kit (Thermo Fisher Scientific, Waltham, MA, USA), and bovine serum albumin was used as a standard. Samples were separated by sodium dodecyl sulfate-polyacrylamide gel electrophoresis, and then proteins were transferred onto an Amersham Hybond PVDF membrane (GE Healthcare, Little Chalfont, UK). After a blocking procedure, the membrane was incubated with anti-mPGES-1 (No. 160140; Cayman Chemicals, Ann Arbor, MI, USA), anti-cPGES (No. 160150; Cayman Chemicals), anti-COX-2 (No. 160106; Cayman Chemicals), anti-COX-1 (NAB37401; R\&D Systems, Minneapolis, MN, USA), or anti- $\beta$-actin (clone 2F3; Fujifilm Wako Pure Chemical, Osaka, Japan) antibody and then incubated with a secondary antibody coupled to horseradish peroxidase (Jackson ImmunoResearch Laboratories, PA, USA). After washing, protein was detected by enhanced chemiluminescence (GE Healthcare, Little Chalfont, UK).

\section{Measurement of $\mathrm{PGE}_{2}$ and $\mathrm{PGD}_{2}$}

Tissues were homogenized in $70 \%$ methanol supplemented with $30 \mu \mathrm{M}$ indometacin. The homogenates were centrifuged at $15,000 \mathrm{~g}$ at $4{ }^{\circ} \mathrm{C}$ for $20 \mathrm{~min}$. The supernatant was evaporated under a nitrogen gas stream and suspended in enzyme immunoassay buffer, and the levels of $\mathrm{PGE}_{2}$ and $\mathrm{PGD}_{2}$ as a MOX-PGD (a stable metabolite of $\mathrm{PGD}_{2}$ ) were measured by enzyme-linked

Table 1 Primer sequences of various target genes for real-time PCR.

\begin{tabular}{|c|c|c|}
\hline Target gene & Sense primer & Antisense primer \\
\hline mPGES-1 & 5'-AGCACACTGCTGGTCATCAA-3' & 5'-CTCCACATCTGGGTCACTCC-3' \\
\hline $\operatorname{cox}-2$ & 5'-AGGACTCTGCTCACGAAGGA-3' & 5'-TGACATGGATTGGAACAGCA-3 \\
\hline CPGES & 5'-TGITGCGAAAAGGAGAATCCG-3' & 5'-ACCCATGTGATCCATCATCTCA-3' \\
\hline COX-1 & 5'-GCCAGAACCAGGGTGTCTGT-3' & 5'-GTAGCCCGTGCGAGTACAATC-3' \\
\hline$E P_{1}$ & 5'-TGCCTCATCCATCACTTC-3' & 5'-ACCACCAACACCAGCAG-3' \\
\hline$E P_{2}$ & 5'-TATGCTCCTTGCCTTCAC-3' & 5'-GACAACAGAGGACTGAGCG-3' \\
\hline$E P_{3}$ & 5'-GCTGTCCGTCTGTTGGTC-3' & 5'-ССТТТТСТTТССАTCTG-3' \\
\hline$E P_{4}$ & 5'-CATCTTACTCATCGCCACC-3' & 5'-ATGTAAATCCAGGGGTCCA-3’' \\
\hline Occludin & 5'-AAGCAAGTTAAGGGATCTGC-3' & 5'-CAGATTAGAGTCCAAAGTCA-3' \\
\hline Claudin-1 & 5'-CCCCATCAATGCCAGGTATG-3' & 5'-CACCTCCCAGAAGGCAGAGG-3' \\
\hline IL-17A & 5'-CAGGGAGAGCTTCATCTGTGT-3' & 5'-GCTGAGCTTTGAGGGATGAT-3' \\
\hline IFNY & 5'-CGGCACAGTCATTGAAAGCCTA-3' & 5'-GTTGCTGATGGCCTGATTGTC-3' \\
\hline $\mathrm{IL}-2$ & 5'-CCTGAGCAGGATGGAGAATTACA-3' & 5'-TCCAGAACATGCCGCAGAG-3' \\
\hline TNFa & 5'-TCCCCAAAGGGATGAGAAG-3' & 5'-CACTTGGTGGTITGCTACGA-3' \\
\hline$\| L-1 \beta$ & 5'-ACTGTGAAATGCCACCTITG-3' & 5'-TGTTGATGTGCTGCTGCGAG-3' \\
\hline IL-6 & 5'-TCCAGTTGCCTTCTTGGGAC-3' & 5'-GTGTAATTAAGCCTCCGACTTG-3’ \\
\hline TGF $\beta 1$ & 5'-CTTCAATACGTCAGACATTCGGG-3' & 5'-GTAACGCCAGGAATTGTTGCTA-3' \\
\hline IL-23p19 & 5'-CCAGCAGCTCTCTCGGAATC-3' & 5'-CGGATCCTITGCAAGCAGAA-3' \\
\hline IL-12/23p40 & 5'-TGGGAGTACCCTGACTCCTG-3' & 5'-GGAACGCACCTTTCTGGTTA-3' \\
\hline IL-12p35 & 5'-AGTTGGCCAGGGTCATTCC-3' & 5'-CAGGTTCGGGACTGGCTAAGA-3' \\
\hline IL-10 & 5'-GGTTGCCAAGCCTTATCGGA-3' & 5'-ACCTGCTCCACTGCCTTGCT-3' \\
\hline Bak & 5'-GATGATATTAACCGGCGCTACG-3' & 5'-CAGCTGATGCCACTCTTAAATA-3' \\
\hline Bid & 5'-TAGGCGATGAGATGGACCACAA-3' & 5'-GGAAGGCTGTCTTCACCTAGTC-3' \\
\hline Bim & 5'-GATCGGAGACGAGTTCAACGAA-3' & 5'-TTCTCCATACCAGACGGAAGAT-3' \\
\hline Bad & 5'-GACGGGCAGCCACCAACAGTCAT-3' & 5'-AAGGGCTAAGCTCCTCСTCCAT-3' \\
\hline Noxa & 5'-GTGGAGTGCACCGGACATAACT-3' & 5'-TGAGCACACTCGTCCTTCAAGT-3' \\
\hline $\mathrm{BCl} 2$ & 5'-ACAACATCGCCCTGTGGATGAC-3' & $5^{\prime}-C A G A G A C A G C C A G G A G A A A T C A-3^{\prime}$ \\
\hline GAPDH & 5'-GTCTTCACCACCATGGAGAAGG-3' & 5'-TCATGGATGACCTTGGCCAG-3' \\
\hline
\end{tabular}


immunosorbent assay kits (Cayman Chemicals, Ann Arbor, MI, USA), according to the manufacturer's protocol [36]. Optical density was measured with the Benchmark microplate reader (Biorad, Hercules, CA, USA).

\section{Immunofluorescence double staining}

Colons (obtained by the adapted Swiss roll technique) were embedded in OCT compound, snap-frozen, and stored at $-80{ }^{\circ} \mathrm{C}$. Cryostat sections $(10 \mu \mathrm{m})$ were fixed in cold acetone and stained with an anti-mPGES-1 monoclonal antibody (ab180589, Abcam, Cambridge, UK) and Alexa Fluor 594-conjugated anti-E-cadherin (clone DECMA-1, a marker of epithelial cells; BioLegend, San Diego, CA, USA), Alexa Fluor 594-conjugated anti-CD3 (clone 17A2, a marker of T cells; BioLegend) or Alexa Fluor 594-conjugated anti-CD11b (clone M1/ 70, a marker of monocytes/macrophages; BioLegend). For the staining of mPGES-1, sections were followed by incubation with Alexa Fluor 488-conjugated secondary antibody (Jackson ImmunoResearch) (West Grove, PA, USA). Color images were obtained by BX51 fluorescence microscope (Olympus Corporation, Tokyo, Japan).

\section{Isolation of lamina propria mononuclear cells and splenocytes}

Lamina propria mononuclear cells (LPMCs) were isolated according to the modified method in a previous report [37]. Briefly, colon tissues were obtained from WT and mPGES- $1^{-/-}$mice on day 7 after the start of exposure to DSS, washed with cold PBS and cut into $1-\mathrm{cm}$ pieces. The pieces were treated with $5 \mathrm{mM}$ EDTA and 1 mM dithiothreitol in Hanks balanced salt solution to remove the epithelial cells, and then the residues were digested with $1.5 \mathrm{mg} / \mathrm{mL}$ collagenase $\mathrm{D}$ (Roche diagnostics, Rotkreuz, Switzerland) and $0.05 \mathrm{mg} / \mathrm{mL}$ DNase I (Roche diagnostics). The dispersed cells were separated in a Percoll gradient to obtain LPMCs. Splenocytes were also isolated, as described in a previous study [26].

\section{Flow cytometry (FCM) analysis}

LPMCs and splenocytes were incubated with anti-CD16/ 32 antibody (TruStain fcX; BioLegend) to block FcyII/III receptor-mediated nonspecific antibody binding before surface staining of cell surface markers. Cells were then stained with fluorochrome-conjugated anti-mouse monoclonal antibodies (BioLegend) against CD3 (clone 17A2) and CD4 (clone GK1.5) before intracellular staining for interferon- $\gamma$ (IFN $\gamma$ ) and IL-17A. Isotype controls were also used to characterize the background signal from off-target antibody binding. The Zombie Aqua Fixable Viability kit (BioLegend) was used in all analyses to remove dead cells and avoid background or unspecific staining of dead cells. For staining of IL-17A- and IFN $\gamma$ producing $\mathrm{T}$ cells, intracellular staining for IFNY (clones
XMG1.2; Biolegend) and IL-17A (TC11-18H10.1; Biolegend) was performed after stimulation of cells, staining of surface molecules, and fixation and permeabilization of cells. Briefly, single-cell suspensions were incubated with phorbol 12-myristate 13-acetate (50 ng/mL, Sigma), ionomycin (500 ng/mL, Sigma), and GolgiStop (BD PharMingen, Franklin Lakes, NJ) for $4 \mathrm{~h}$ in vitro in RPMI1640 supplemented with 10\% fetal bovine serum, penicillin/streptomycin, and freshly added $50 \mu \mathrm{mol} / \mathrm{L} 2$ mercaptoethanol, as described in a previous report [27]. The Cytofix/Cytoperm Plus Fixation/Permeabilization kit (BD PharMingen) was used to fix, permeabilize, and stain cells, in accordance with the manufacturer's instructions. Tregs were detected with the Treg Detection kit (Miltenyi Biotec, Bergisch Gladbach, Germany) with CD3 antibody (clone 17A2), in accordance with the manufacturer's instructions. The stained cells were analyzed by a MACS Quant Analyzer (Miltenyi Biotec). The gating strategy was always in accordance with the following hierarchy: total events $\rightarrow$ lymphocyte gate (FSC$\mathrm{A} / \mathrm{SSC}-\mathrm{A}) \rightarrow$ living cells (Live/Dead-) $\rightarrow \mathrm{CD}^{+} \mathrm{CD} 4^{+}$, with subsequent gating indicated in each experiment.

\section{In vivo $\mathrm{CD} 4$ positive $\mathrm{T}$ cell depletion}

For $\mathrm{CD} 4^{+} \mathrm{T}$ cell depletion experiments, mice are treated with $0.1 \mathrm{mg}$ of anti-CD4 monoclonal antibody (clone GK1.5; Bio X Cell, West Lebanon, New Hampshire) or $0.1 \mathrm{mg}$ of isotype-matched control antibody (clone LTF2; Bio X Cell) via intraperitoneal injections on the days -1 and +3 relative to the start of DSS administration [38]. Depletion of $\mathrm{CD} 4^{+} \mathrm{T}$ cell was confirmed by FCM analysis of $\mathrm{T}$ cell population in the peripheral blood and spleen by staining with fluorochrome-conjugated antimouse monoclonal antibodies (BioLegend) against CD3 (clone 17A2) and CD4 (clone RM4.4), CD8 (clone 536.7) and CD11b (clone M1/70).

\section{In situ apoptosis detection}

Apoptotic cells were detected by in situ apoptosis detection kit (Takara Bio Inc, Shiga, Japan), according to the manufacturer's protocol. Briefly, paraffin-embedded colon sections of $3.5-\mu \mathrm{m}$ thickness (obtained by the adapted Swiss roll technique) were incubated with a terminal dexoynucleotidyl transferase enzyme and then with an anti-FITC peroxidase-conjugated secondary antibody. The positive signals were visualized with 3,3'diaminobenzidine (Takara DAB substrate: Takara Bio Inc, Shiga, Japan), and then sections were counterstained with methyl green.

\section{Statistical analysis}

Data were expressed as the means \pm SEM. Statistical analysis was performed with the Sigmastat 3.5 software (Systat Software, Inc., San Jose, CA, USA). Data from 
more than two groups were compared by 2-way analysis of variance (ANOVA) followed by Tukey multiple comparison test, and data from 2 groups were compared by $t$ test after testing for normal distribution. $P<0.05$ was considered statistically significant.

\section{Results}

Exacerbated DSS-induced colitis in mice with mPGES-1 genetic deletion

mPGES- $1^{-1-}$ and WT mice were given a relatively low dose of 1\% DSS for 7 days, and the severity of colitis was daily evaluated for a week. As shown in Fig. 1A, after 7 days' administration of $1 \%$ DSS, body weight was significantly lower in the mPGES- $1^{-1-}$ mice than in the WT mice. In addition, both genotypes of $1 \%$ DSS-treated mice exhibited diarrhea and fecal bleeding, but these colitis symptoms were more severe in $\mathrm{mPGES}-1^{-1-}$ mice than in WT mice. The total DAI colitis scores were also markedly higher in mPGES- $1^{-1-}$ mice than in WT mice, as were the separate scores for stool consistency and bleeding. Weekly food uptake was significantly lower in mPGES- ${ }^{-1-}$ mice than in WT mice. Uptake of DSS-

\section{A}
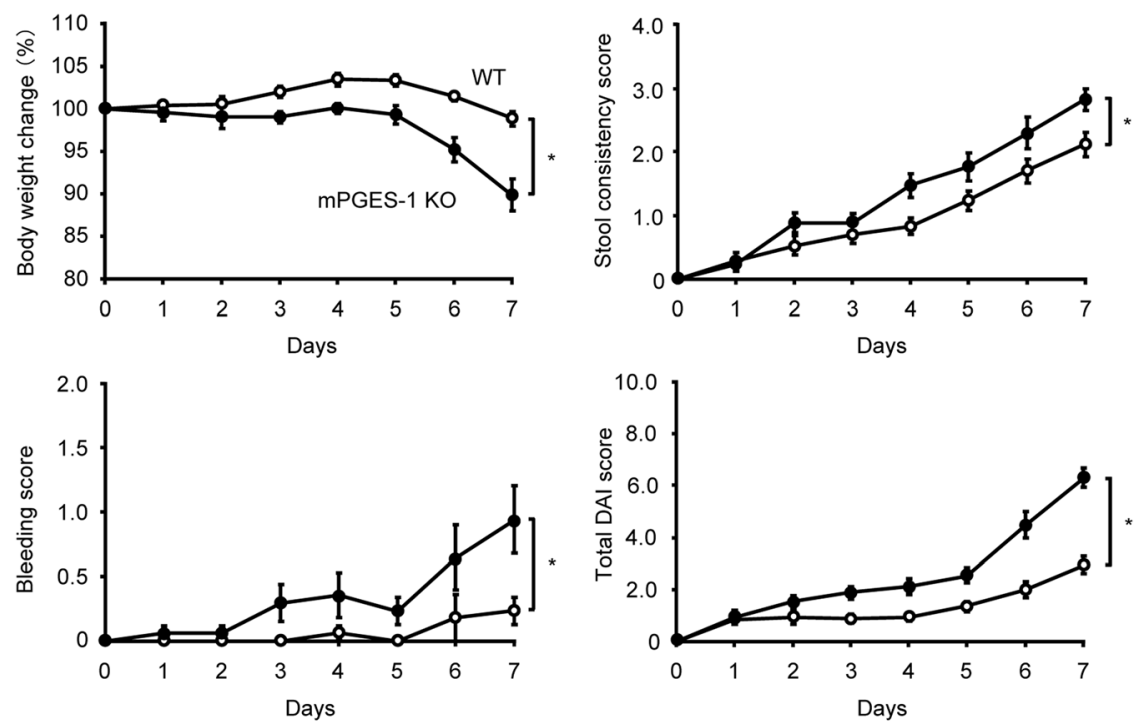

B
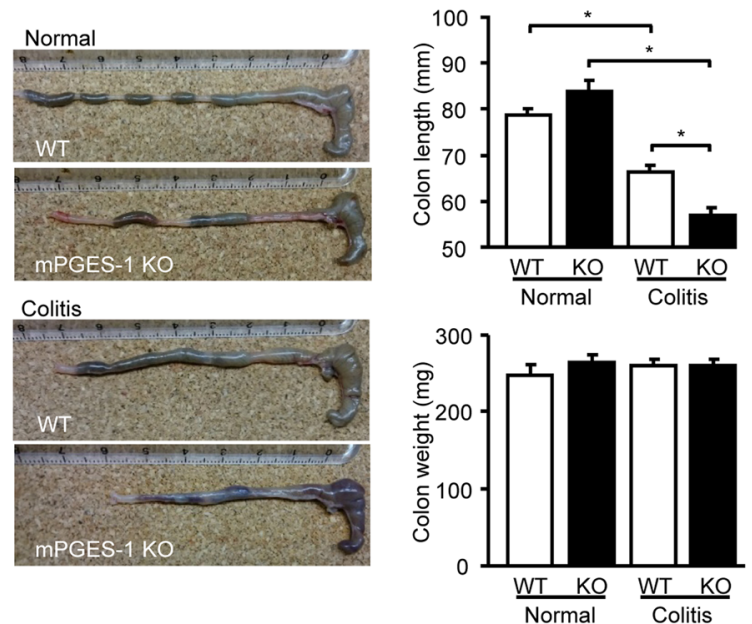

Fig. 1 Clinical course of DSS-induced colitis in mice with a mPGES-1 genetic deletion. A Time course of change in body weight, stool consistency, bleeding score, and total disease activity index (DAl) score of WT and mPGES-1 $1^{-1-}$ mice after indicated days of exposure to $1 \%$ DSS $(n=17)$. B On day 7 after the start of exposure to $1 \%$ DSS, the length and weight of the colon were measured as an indirect marker of inflammation ( $n=3$ to 17). Pictures of the colon are representative examples in WT and mPGES- $1^{-1-}$ mice. ${ }^{*} P<0.05 ; 2$-way ANOVA followed by Tukey multiple comparison test 
containing water did not differ between WT and mPGES- $1^{-/-}$mice, although the latter showed a trend towards consuming less water (Fig. S1). Experiments were mainly performed by using female mice in this study, but the total DIA scores of male mPGES-1 $1^{-1-}$ mice were also significantly higher in male WT mice after 7 days' administration of 1\% DSS (WT: $5.5 \pm 0.6(n$ $=4)$, PPGES$^{-1-}{ }^{-1}: 8.4+0.5(n=5)$ on Day $7\left({ }^{*} P<0.05\right.$; $t$ test)).

Colon shortening has been proven to be a useful inflammatory marker and indicator of colitis [39]. Consistent with the total DAI score, by day 7, both genotypes of DSS-treated mice showed colon shortening, but the colon was significantly shorter in the $\mathrm{mPGES}-1^{-1-}$ mice than in the WT mice (Fig. 1B). No significant differences in colon weight were observed between the genotypes and DSS administered.

Notably, only approximately $60 \%$ of $\mathrm{mPGES}-1^{-1-}$ mice (8 of 13 mice) survived after 7 days' exposure to the higher dose of $2 \%$ DSS, but all WT mice (12 of 12 mice) survived. Thus, the subsequent experiments in the $2 \%$ DSS-treated $\mathrm{mPGES}-1^{-/}$mice were continued in only survived mice until day 7 of exposure to DSS.

\section{Histological features of DSS-induced colitis in $\mathrm{mPGES}-1^{-/-}$ mice}

Severity of colitis was further assessed by histological evaluation with $H \& E$-stained colon sections. As shown in Fig. 2A, after DSS administration, the colons of WT mice showed the characteristic features of colitis, with extensive areas of mononuclear infiltrates, focal crypt epithelial destruction, and edema. Compared with WT mice, mPGES-1 ${ }^{-/-}$mice showed greater epithelial damage and infiltration of inflammatory cells. After grading of these histological features by an observer blinded to the genotypes of the sections, the sum of the epithelial damage and inflammatory infiltration scores was significantly higher in $\mathrm{mPGES}-1^{-/-}$mice than in WT mice (Fig. 2B).

To characterize the protective effect of mPGES-1 on the epithelial layer in DSS-treated mice, we quantified the permeability by orally administering FITC-dextran to mice and measuring the serum levels. On day 7 after the start of DSS administration, significantly more FITC-dextran diffused through the epithelium in mPGES-1 $1^{-/-}$mice than in WT mice (Fig. 2C). DSS treatment resulted in a decrease in the colonic mRNA expression level of the tight junction molecules occludin and claudin-1, which play crucial roles in regulating intestinal paracellular permeability [40], but the differences in the expression levels of these molecules between WT and $\mathrm{mPGES}-1^{-/-}$mice did not reach statistical significance in this study (Fig. 2D).

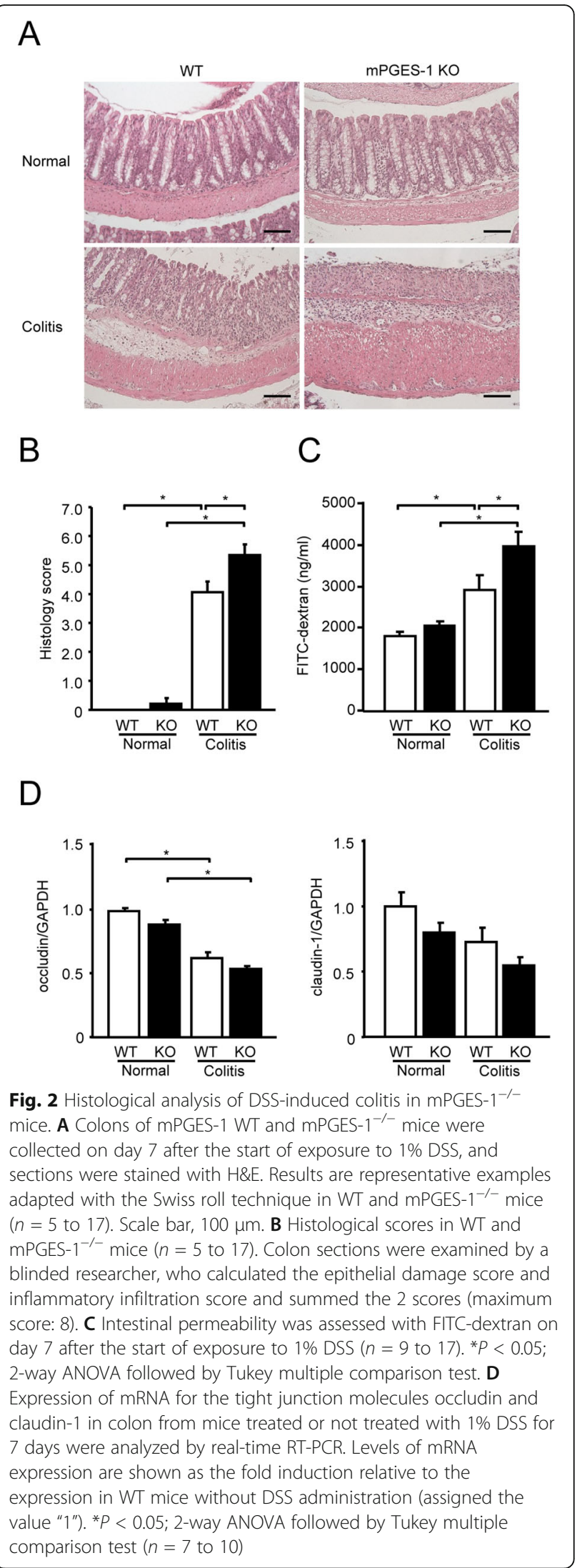


mPGES-1 ${ }^{-/-}$mice display anemia and extramedullary hematopoiesis in spleen

mPGES-1 $1^{-/-}$mice exhibited marked splenomegaly by day 7 after the start of DSS administration, as shown in Fig. 3A. The weight of the spleens indicated that the spleens of $\mathrm{mPGES}-1^{-1-}$ mice were approximately 2.5 fold larger after administration of DSS, but the spleens of WT mice were not affected by DSS. In mPGES-1 ${ }^{-/-}$ mice, histological examination of the spleen after DSS administration showed massive expansion of the red pulp along with increased cellularity compared with WT mice (Fig. 3B). The expansion of splenic red pulp, along with increased cellularity, represents a key feature of enhanced extramedullary hematopoiesis in the spleen [41, 42] and also generally represents a valid cause of an enlarged spleen with extramedullary hematopoiesis [43, 44 ]. In severe colitis after long-term, repeated DSS treatment, splenic extramedullary hematopoiesis is increased, as reflected by increases in spleen weights and the red pulp, resulting in increased reticulocyte counts in

A

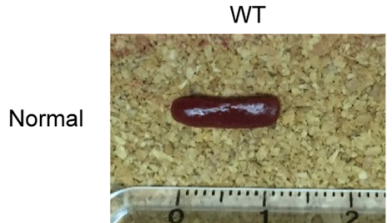

MPGES-1 KO
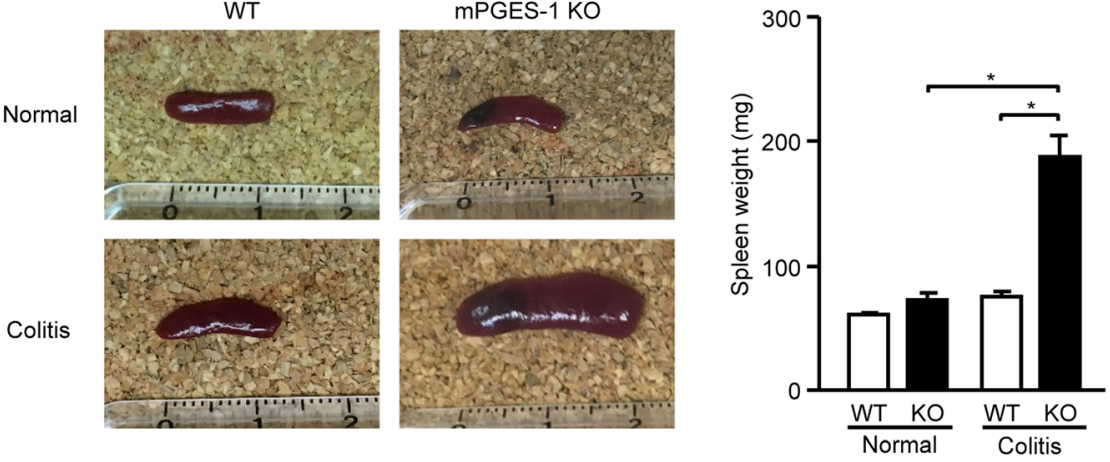

B

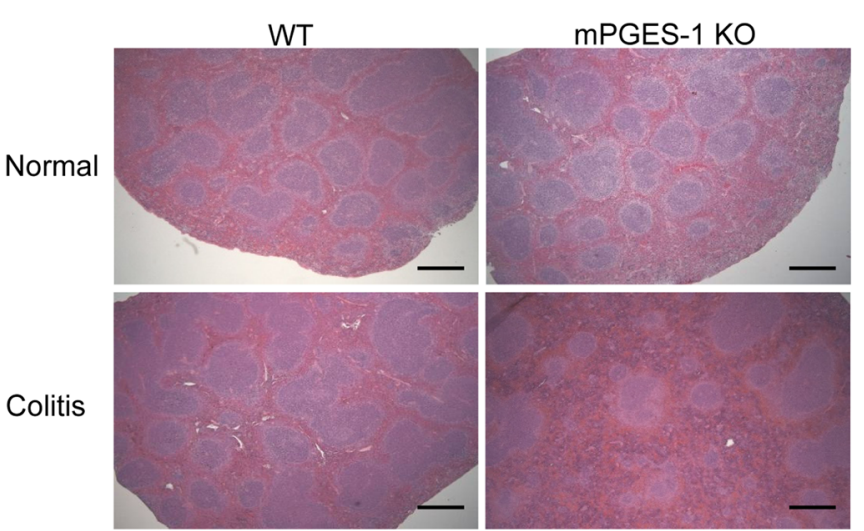

C
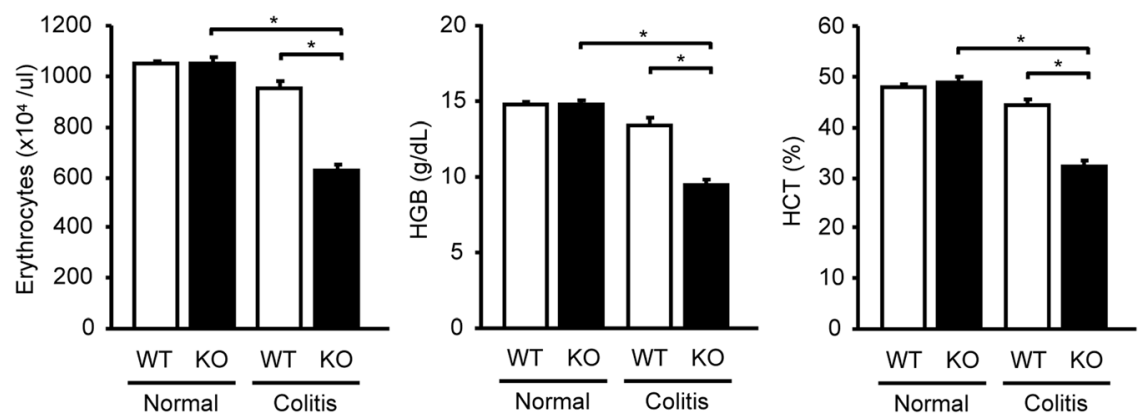

Fig. 3 Analysis of splenomegaly and anemia in $\mathrm{mPGES}-1^{-1-}$ mice. A Spleen was isolated, imaged and weighed on day 7 after the start of exposure to 1\% DSS. B Also on day 7, morphological analysis of the spleen was performed by H\&E staining. Representative images are shown. Scale bar, $500 \mu \mathrm{m}$. C Erythrocyte count, hemoglobin (HGB) concentration, and hematocrit (HCT) in the peripheral blood were measured on day 7 after the start exposure to $1 \%$ DSS. ${ }^{*} P<0.05$; 2-way ANOVA followed by Tukey multiple comparison test $(n=3$ to 17) 
response to anemia [45]. Indeed, mPGES-1 ${ }^{-/-}$mice showed significantly decreased erythrocytes and lower levels of HGB and HCT in peripheral blood, indicating severe anemia after DSS administration (Fig. 3C). The splenomegaly and extramedullary hematopoiesis might be linked with the anemia associated with gastrointestinal hemorrhage during severe colitis in the absence of mPGES-1.

In the subpopulation analysis of splenocytes from mice with colitis, we found no differences in the number of $\mathrm{CD}_{19}{ }^{+}, \mathrm{CD}_{11} \mathrm{c}^{+}, \mathrm{CD}_{11} \mathrm{~b}^{+}$, or $\mathrm{Gr}-1^{+}$cells between WT and $\mathrm{mPGES}-1^{-/-}$mice (Table S1). We did not detect any evidence of enhanced immunity in the enlarged spleen of $\mathrm{mPGES}-1^{-/-}$mice with colitis.

\section{Induction of mRNA expression for MPGES-1 and COX-2 in DSS-induced colitis}

Because we observed greater severity of DSS-induced colitis in mPGES- $^{-1-}$ mice, we next determined the mRNA expression of PG biosynthetic enzymes in the colon from WT and mPGES-1 ${ }^{-/-}$mice with or without DSS administration (Fig. 4A). In WT mice, colonic expression of mPGES-1 mRNA was basally detectable and significantly increased in a dose-dependent manner at 7 days after the start of DSS administration. As expected, mPGES-1 expression was completely abolished in mPGES- $1^{-1-}$ mice either with or without DSS administration. The colonic expression of cPGES, a constitutive isozyme of PGES, was not changed by DSS treatment in either the WT or mPGES-1 $1^{-/-}$mice. Colonic expression of COX-2 mRNA was significantly increased by DSS in both WT and mPGES- $^{-/-}$mice in a concentrationdependent manner, and the level of COX-2 expression in $\mathrm{mPGES}-1^{-/-}$mice was significantly higher than in WT mice. COX-1 was also expressed in the colon, but the expression level was similar in both $\mathrm{mPGES}-1^{-/-}$and WT mice.

After DSS administration, the expressions of $\mathrm{EP}_{1}, \mathrm{EP}_{3}$, and $\mathrm{EP}_{4}$ decreased significantly over time in both WT and mPGES- ${ }^{-/-}$mice, but the expression of $\mathrm{EP}_{3}$ decreased faster in $\mathrm{mPGES}^{-1^{-1}}$ mice than in WT mice (Fig. 4B). In addition, the mPGES-1 $1^{-1-}$ mice showed increased $\mathrm{EP}_{2}$ expression on day 7 after the start of DSS administration.

\section{Expression and localization of MPGES-1 and prostanoid production in the colon}

We next examined the protein expression of $\mathrm{PGE}_{2}$ biosynthetic enzymes in the colon (Fig. 5A). The colon of WT mice basally expressed a low level of mPGES-1 protein, and expression of mPGES-1 was upregulated in response to DSS (Fig. 5A). As expected, the colon of mPGES- $1^{-1-}$ mice did not express mPGES-1 protein, either with or without DSS administration. In addition,
COX-2 protein was not detected without DSS administration, but it was significantly induced by DSS in both WT and mPGES- $1^{-1-}$ mice. The induction of COX-2 was greater in $\mathrm{mPGES}-1^{-1-}$ mice than in WT mice. On the other hand, cPGES and COX-1 protein were present without DSS administration in both WT and mPGES$1^{-/-}$mice, and the expression of these proteins did not change after induction of colitis. These results were well consistent with the mRNA expression patterns of each enzyme.

We next determined the role of mPGES-1 in colonic prostanoid production under normal and colitis state. As shown in Fig. 5B, the basal level of colonic $\mathrm{PGE}_{2}$ without induction of colitis was low in WT mice. After DSS administration, the level of colonic $\mathrm{PGE}_{2}$ increased significantly in WT mice in a concentration-dependent manner but did not increase in mPGES- ${ }^{-1-}$ mice. Notably, even in non-inflamed colon without DSS, mPGES1 genetic deletion resulted in greater reduction of colonic $\mathrm{PGE}_{2}$ when compared with WT mice. These data clearly indicate that $\mathrm{mPGES}-1$ is the main synthase responsible for colonic $\mathrm{PGE}_{2}$ production not only in colitis but also in the healthy condition. A minimal level of $\mathrm{PGE}_{2}$ was still detectable in mice without mPGES-1, indicating that CPGES and other PGES isozymes other than mPGES-1 contribute somewhat to colonic $\mathrm{PGE}_{2}$ production.

To further determine whether there was compensatory shunting of arachidonic acid into other prostanoid pathways in the $\mathrm{mPGES}^{-1^{-/}}$mice, we also measured the level of colonic $\mathrm{PGD}_{2}$, known as an anti-colitis prostanoid $[16,46]$. WT and $\mathrm{mPGES}-1^{-1-}$ mice displayed similar baseline levels of $\mathrm{PGD}_{2}$ in the colon; however, DSS administration resulted in a marked increase of colonic $\mathrm{PGD}_{2}$ production in $\mathrm{mPGES}-1^{-/}$mice but not in WT mice (Fig. 5B).

In our immunohistochemical analysis of WT mice to identify the site responsible for $\mathrm{PGE}_{2}$ production in the colon during colitis, we detected mPGES-1 fluorescence immunoreactivity in the colonic mucosal epithelium and infiltrated inflammatory cells in underlying connective tissues and the lamina propria (LP) of WT mice (Fig. 5C). Double staining for mPGES-1 (green) and Ecadherin, CD3 or CD11b (red), showed mPGES-1 immunoreactivity mostly colocalized with immunoreactivity of an epithelial cell marker, E-cadherin, a $\mathrm{T}$ cell marker CD3 and a monocytes/macrophage marker $\mathrm{CD} 11 \mathrm{~b}$ in the colon. In the negative control, which used the frozen colon section of mPGES- $1^{-/-}$mice, we did not detect immunoreactivity in the colonic mucosal epithelium and infiltrated inflammatory cells in underlying connective tissues and the LP, but likely nonspecific immunoreactivity was detected only in the colonic muscular layer (data not shown). These data suggest that the 
A
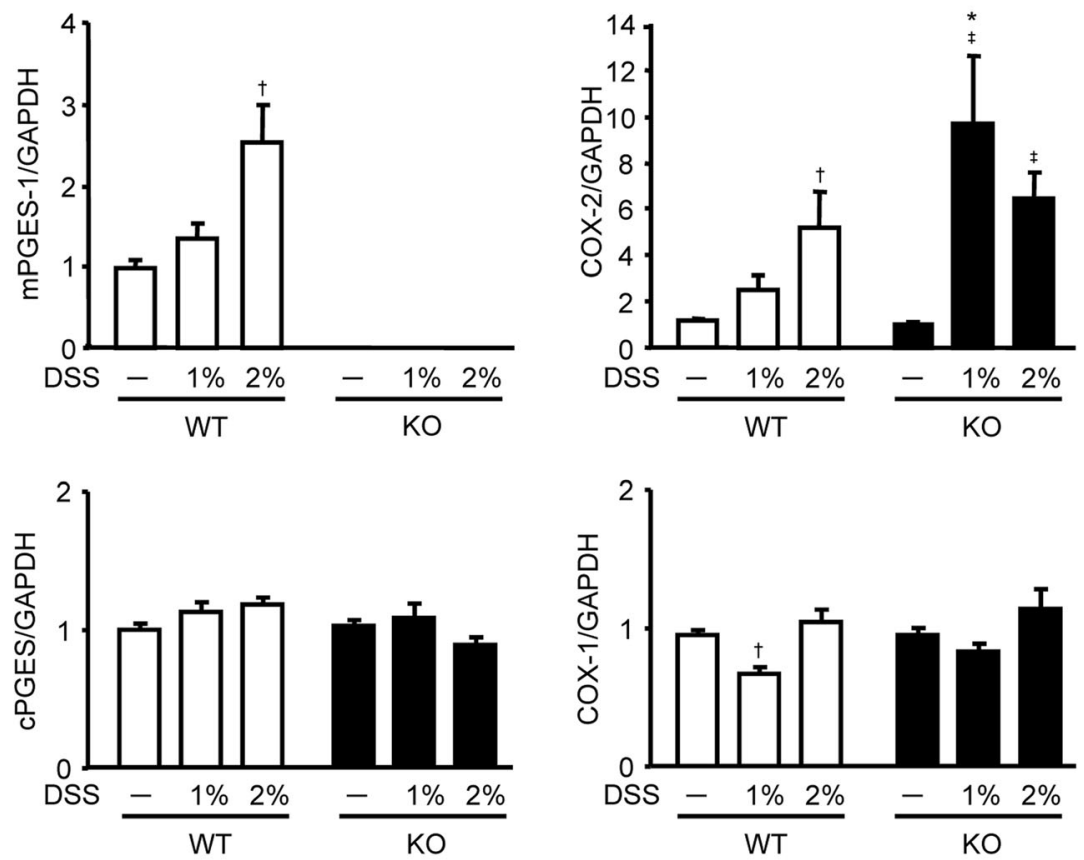

B
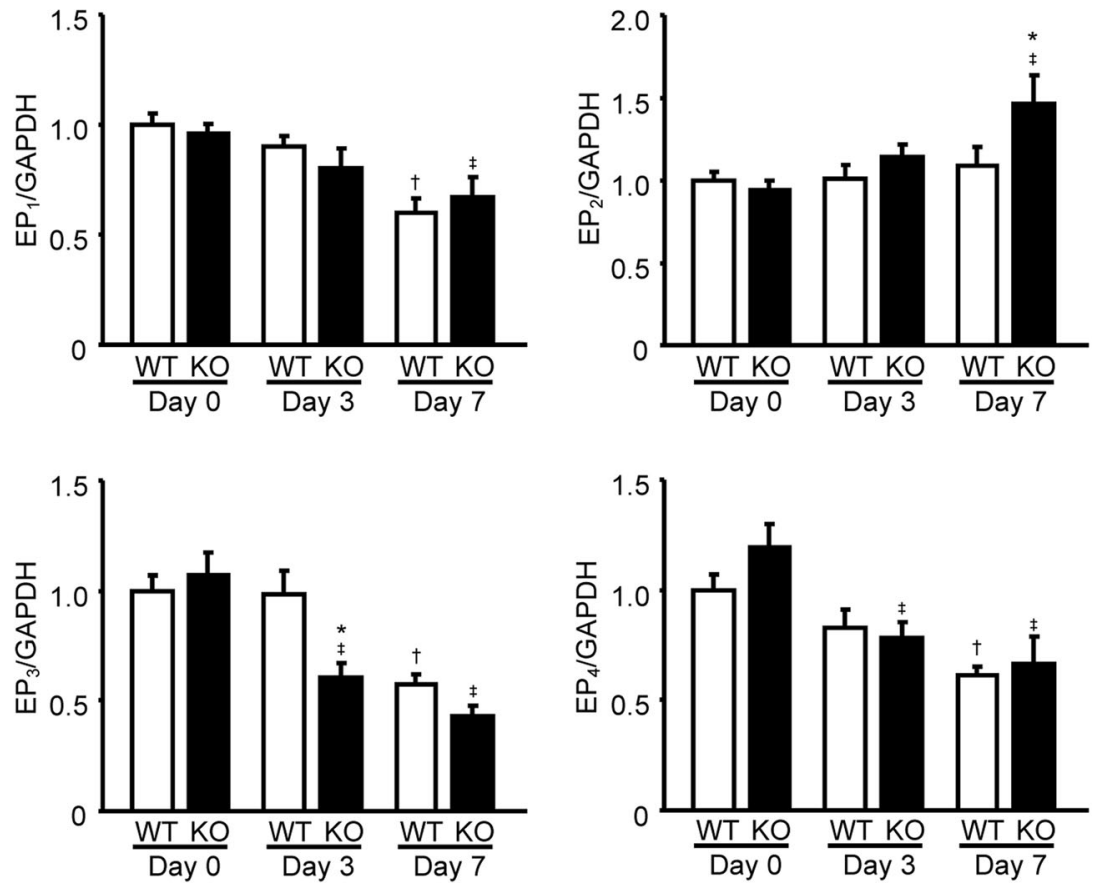
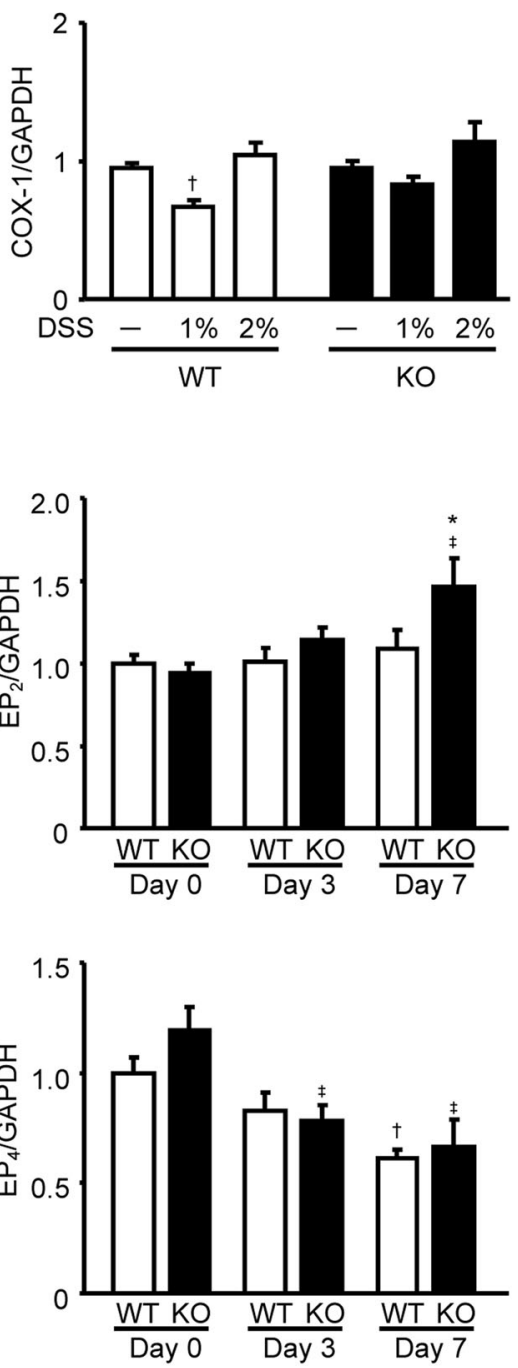

Fig. 4 Expressions of $m R N A$ for $P G E_{2}$ biosynthetic enzymes and EP receptor subtypes in colon after exposure to DSS. A Expression of $m R N A$ for PGES and COX isozymes in colon from mice treated or not treated with the indicated dose of DSS for 7 days were analyzed by real-time RT-PCR ( $n=7$ to 12). Levels of mRNA expression are shown as the fold induction relative to the expression in WT mice without DSS administration (assigned the value " 1 "). ${ }^{*} P<0.05$ vs WT mice within each day, ${ }^{\dagger} P<0.05$ vs non-DSS-treated WT mice, and ${ }^{\ddagger} P<0.05$ vs non-DSS-treated KO mice; 2-way ANOVA followed by Tukey multiple comparison test. B Expression of EP receptor mRNA in colon from mice treated with 1\% DSS for indicated days was analyzed by real-time RT-PCR ( $n=7$ to 10). Levels of mRNA expression are shown as the fold induction relative to day 0 expression in WT (assigned the value " 1 "). ${ }^{*} P<0.05$ vs WT mice within each day, ${ }^{\dagger} P<0.05$ vs WT at day 0 , and ${ }^{\ddagger} P<0.05$ vs KO mice at day 0 ; 2 way ANOVA followed by Tukey multiple comparison test 


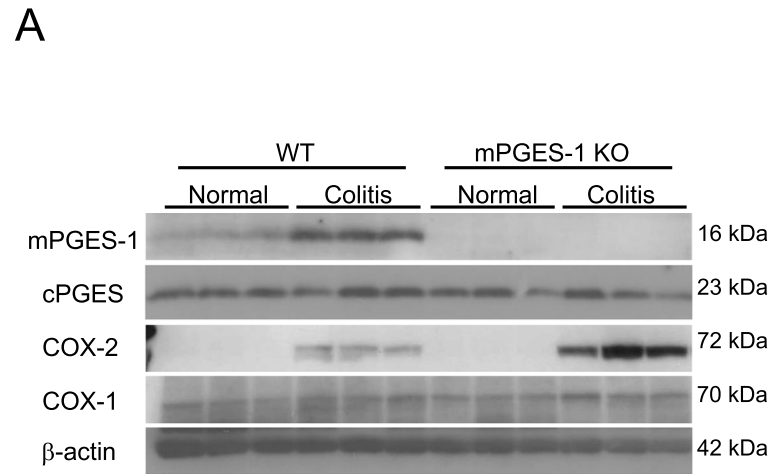

C
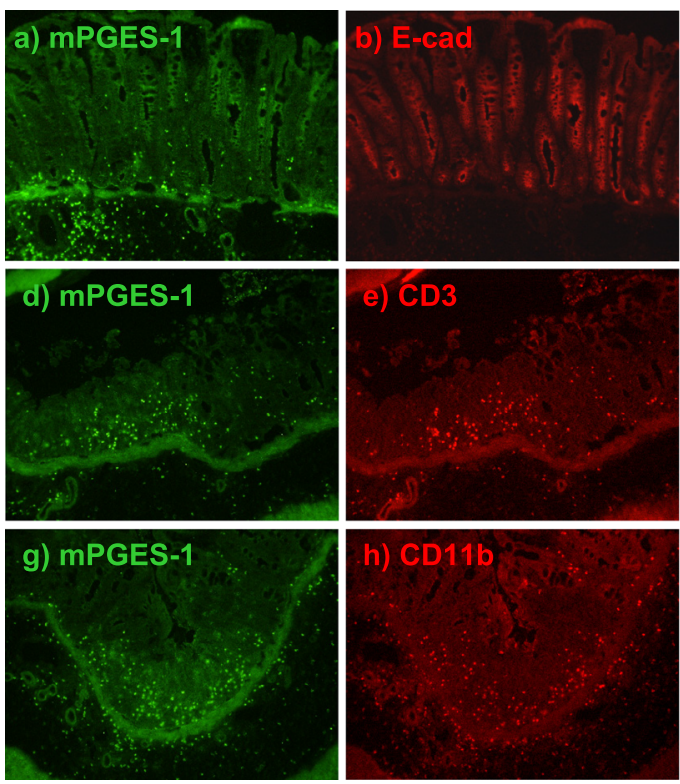

B


Fig. 5 mPGES-1 protein expression and prostanoid production in the colon with colitis by DSS. A Expression of protein for PGES and COX isozymes in colon on day 7 after the start of exposure to $1 \%$ DSS were analyzed by western blot analysis $(n=3)$. B The levels of PGE 2 and PGD 2 in the colon from mice treated or not treated with the indicated dose of DSS for 7 days were measured by ELISA. * $P<0.05$ vs WT mice within each day, ${ }^{\dagger} P<0.05$ vs non-DSS-treated WT mice, and ${ }^{\ddagger} P<0.05$ vs non-DSS-treated KO mice; 2-way ANOVA followed by Turkey multiple comparison test ( $n=3$ to 5). C Representative double immunofluorescence staining image of Swiss-roll colon sections of WT mice on day 7 after the start of exposure to 1\% DSS. Double staining for mPGES-1 (green) and E-cadherin, CD3 or CD11b (red) showed mPGES-1 immunoreactivity mostly colocalized with an epithelial cell marker, E-cadherin, a T cell marker CD3 and a monocytes/macrophage marker CD11b in the colon

overexpression of mPGES-1 in the mucosal epithelium, immune cells, and inflammatory cells at inflammatory sites could be responsible for elevated $\mathrm{PGE}_{2}$ production in the colon during colitis.

\section{Facilitation of colonic Th17/Th1-related cytokine expression in mPGES-1 deficiency}

To clarify the mechanism how mPGES-1 exerts protective effect on the colitis, we next turned our attention to a $\mathrm{T}$ cell immunologic response which is an essential event in experimental colitis as well as IBD. As shown in Fig. 6, the colons of mPGES-1 $1^{-1-}$ mice expressed markedly higher levels of mRNA for IL-17A (Th17 cytokine) and IFN $\gamma$ and IL-2 (Th1 cytokines) than the colons of WT mice after 7 days' administration of $1 \%$ DSS. Notably, after treatment with high dose of $2 \%$ DSS the colonic expressions of IL-17A and IFN $\gamma$ mRNA were also higher in $\mathrm{mPGES}-1^{-1-}$ mice compared with those in WT 

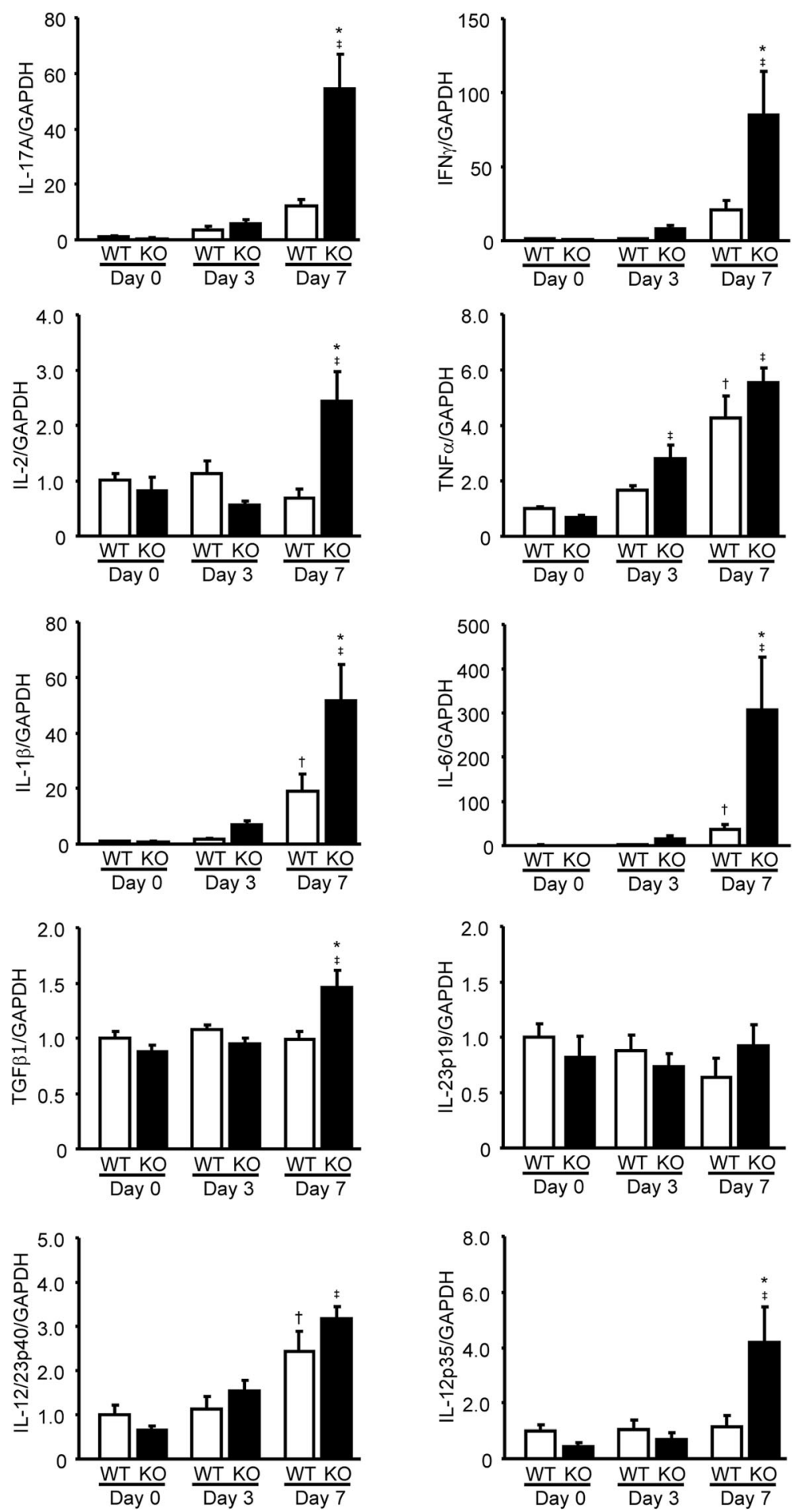

Fig. 6 Colonic expression profile of Th17/Th1-related cytokines in mPGES-1 ${ }^{-1-}$ mice with DSS-induced colitis. Expressions of mRNA for IL-17A, IFNY, IL-2, TNFa, IL-1 $\beta$, IL-6, TGFß1, IL-23p19, IL-12/23p40, and IL-12p35 in colon from mice treated with 1\% DSS for indicated days were analyzed by real-time RT-PCR ( $n=7$ to 10). Levels of mRNA expression are shown as the fold induction relative to day 0 expression in WT mice (assigned the value " 1 "). ${ }^{*} P<0.05$ vs WT mice within each day, ${ }^{\dagger} P<0.05$ vs non-DSS-treated WT mice, and ${ }^{\ddagger} P<0.05$ vs non-DSS-treated KO mice; 2 -way ANOVA followed by Tukey multiple comparison test 
mice (IL-17: WT $112.6 \pm 23.9(n=12)$, KO $210.1 \pm 60.7$ $(n=8) ;$ IFNy: WT $16.4+6.7(n=12), \mathrm{KO} 46.5+19.5$ $(n=8))$. In addition, the colonic expressions of the major proinflammatory cytokines IL-1 $\beta$ and IL-6, which are also known to be essential for Th17 cell differentiation from naive $\mathrm{CD}^{+} \mathrm{T}$ cells $[47,48]$, were higher in mPGES- $1^{-/-}$mice. The expression level of TGF $\beta 1$, an essential inducer of Th17 cell differentiation in combination with IL-6 [49], was also higher in mPGES-1 ${ }^{-/-}$ mice than in WT mice. In contrast, the levels of components of IL-23 (IL-23p19 and IL-12/23p40), which were shown to be a requirement for human Th17 differentiation [50], did not differ between WT and mPGES-1 ${ }^{-/-}$ mice. The expression of IL-12p35, a subunit of IL-12 that was reported as being required for IFN $\gamma$-producing Th1 differentiation [51], was significantly higher in mPGES-1 $1^{-1-}$ mice than in WT mice. These results correlated well with the pathophysiological and histopathological evidence of colitis observed under mPGES-1 deficiency in the present study. Taken together, the results suggest that mPGES-1-driven $\mathrm{PGE}_{2}$ suppresses the excessive abnormal immune responses associated with the Th17/Th1-related cytokine during colitis. As unexpected, the colonic expression levels of TNF $\alpha$, one of the major proinflammatory cytokines relevant to IBD, did not differ between WT and mPGES-1 ${ }^{-/-}$mice.

\section{Genetic deletion of mPGES-1 results in enhancing generation of IL-17A- and IFNY-producing T cells}

To further determine the impact of mPGES-1 on the developing Th17 and Th1 immunologic responses associated with colitis, after inducing colitis, we determined the fraction of Th17 and Th1 cells that produced IL-17A and IFN $\gamma$ in cell populations from spleen and LP of the colon from mPGES-1 ${ }^{-/-}$and WT mice. Cells were isolated during colitis, stimulated ex vivo with phorbol 12myristate 13-acetate/ionomycin, then surface stained for CD3/CD4, fixed, stained for intracellular IL-17A and IFNY and analyzed by FCM. As shown in Fig. 7A, in splenocytes in both $\mathrm{mPGES}-1^{-1-}$ and WT mice, we found few Th17 cells that can produce IL-17A. The percentage of IFN $\gamma$-producing Th1 cells in splenocytes was also similar in both genotypes. In addition, the IL$17^{+} \mathrm{IFN}^{+}$double positive cells in splenocytes were few in both $\mathrm{mPGES}-1^{-/-}$and WT mice. However, in the LPMCs from the colon the populations of IL-17Aproducing Th17 cells, IFN $\gamma$-producing Th1 cells and L17 and IFNy double-producing cells within $\mathrm{CD}^{+} \mathrm{CD}^{+}$ cells were larger in $\mathrm{mPGES}-1^{-1-}$ mice than in WT mice (Fig. 7A and B). Compared with WT mice, the numbers of both $\mathrm{CD}^{+} \mathrm{CD}^{+}{ }^{+}$Th17 cells and $\mathrm{CD}^{+} \mathrm{CD}^{+}$Th1 cells within LPMCs were also significantly increased in the colonic LP from mPGES-1 ${ }^{-1-}$ mice (Fig. 7B), which was consistent with facilitation of colonic Th17/Th1-related cytokine expression under mPGES-1 deficiency (Fig. 6).

\section{Increased Treg population and IL-10 expression in mPGES-1 ${ }^{-1-}$ mice during DSS-induced colitis}

We next examined the effect of mPGES-1 genetic deletion on the population of FoxP $3^{+} \mathrm{CD} 25^{+}$Tregs in LPMCs isolated from colons with DSS-induced colitis. The population of FoxP3 ${ }^{+} \mathrm{CD} 25^{+}$Tregs was larger and the number of these cells was higher in $\mathrm{mPGES}-1^{-/-}$mice than in WT mice (Fig. 8). Furthermore, mPGES- $1^{-1-}$ mice showed higher expression of colonic IL-10 (an anti-colitis cytokine also produced by Tregs). These data imply that-in addition to its visible anti-colitis activity through regulation of Th17/Th1 immunity during colitis-mPGES-1driven $\mathrm{PGE}_{2}$ may act as an enhancer of colitis by suppressing anti-colitis activity mediated by Tregs.

\section{Attenuated symptoms of DSS-induced colitis by $\mathrm{CD}^{+} \mathrm{T}$ cell depletion in $\mathrm{mPGES}-1^{-/-}$mice}

To investigate the functional role of $\mathrm{T}$ cells in the exacerbated DSS-induced colitis under mPGES-1 deficiency, the course of DSS-induced colitis in $\mathrm{mPGES}-1^{-/-}$mice were studied upon $\mathrm{CD}^{+} \mathrm{T}$ cell depletion by the treatment with anti-CD4 monoclonal antibody (Clone GK1.5) prior to DSS administration (Fig. 9A). The efficacy of CD4 ${ }^{+} \mathrm{T}$ cell depletion was confirmed by FCM analysis of T cell population in the peripheral blood, spleen, and LPMCs (Figs. $9 \mathrm{~B}$ and $\mathrm{S} 2$ ). The treatment with GK-1.5 effectively reduced the number of $\mathrm{CD}^{+} \mathrm{CD}_{4}^{+} \mathrm{T}$ cell in vivo, whereas control antibody (clone LTF-2) had no effect. Both GK1.5 and LTF-2 did not affect the population of $\mathrm{CD}^{+} \mathrm{CD}^{+} \mathrm{T}$ cells and $\mathrm{CD}_{11 \mathrm{~b}^{+}}$cells (data not shown). As shown in Fig. 9C, the total DAI colitis scores were significantly lower in GK1.5-treated $\mathrm{mPGES}^{-1}{ }^{-/}$mice than in LTF-2-treated mPGES- $1^{-/-}$mice. The colon shortening and splenomegaly in $\mathrm{mPGES}-1^{-/-}$mice were also significantly improved by the treatment with GK1.5 (Fig. 9C and D). These results suggested the requirement of $\mathrm{CD}^{+} \mathrm{T}$ cells in the exacerbation of DSS-induced colitis under mPGES-1 deficiency. Alternatively, even though the colitis and splenomegaly in $\mathrm{mPGES}-1^{-/}$mice were largely suppressed by the treatment of GK1.5, these were remained to be significantly different when compared to GK1.5treated WT mice. The level of IL-17 mRNA was 50\% lower in GK1.5-treated mPGES-1 $1^{-/-}$mice than in LTF-2treated $\mathrm{mPGES}-1^{-1-}$ mice, even though this difference did not reach statistical significance. The levels of IFN $\gamma$ and IL-10 were significantly lower in GK1.5-treated mPGES$1^{-/-}$mice than in LTF-2-treated mPGES-1 $1^{-/-}$mice. These results suggest the contribution of $\mathrm{CD}^{+} \mathrm{T}$ cells in the upregulation of these cytokines during DSS-induced colitis under mPGES-1 deficiency. On the other hand, the colonic expression levels of IL-1 $\beta$ and IL-6, which were 
A



LPMCs

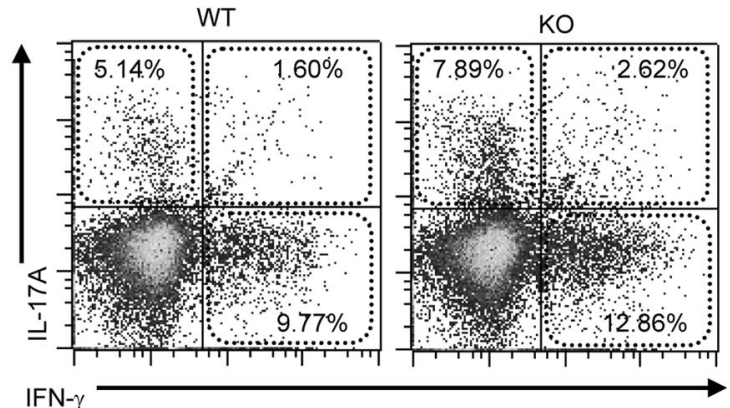

B
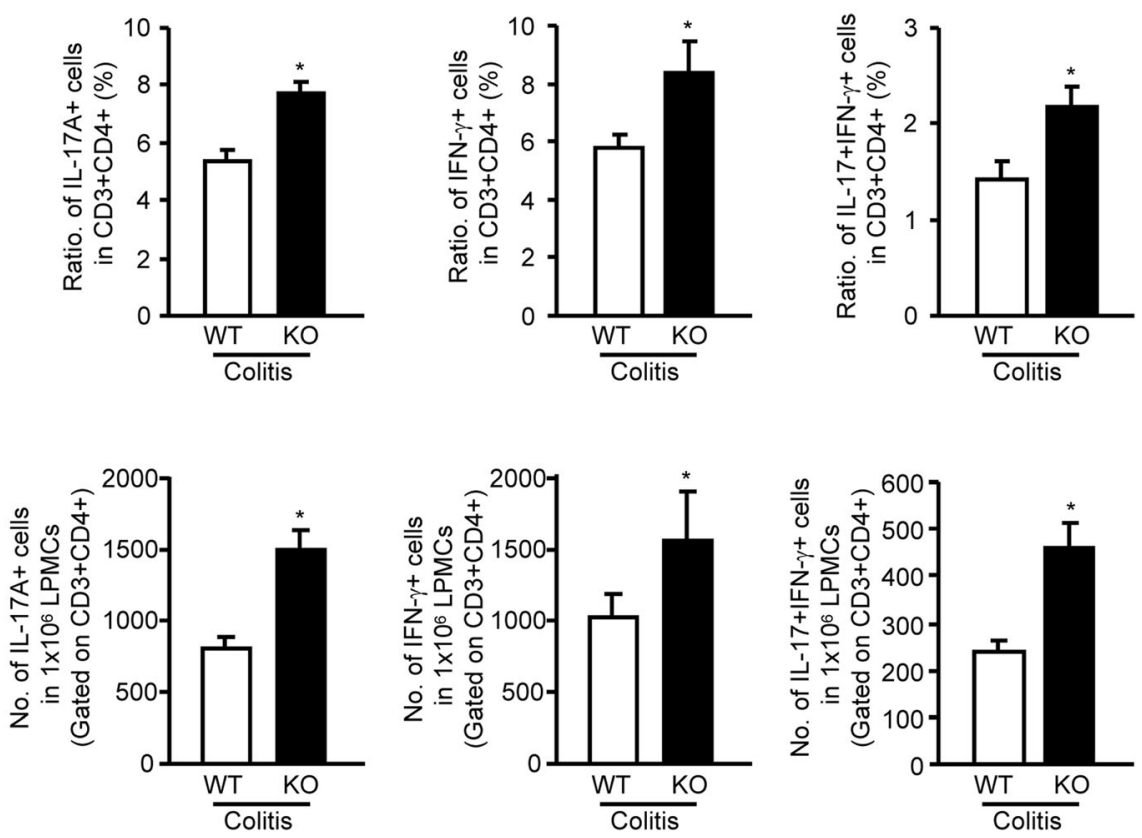

Fig. 7 Generation of IL-17A- and IFNy-producing T cells in colonic LPMCs and splenocytes of MPGES-1 ${ }^{-/-}$mice with DSS-induced colitis. A Representative FCM plot of IL-17A-producing Th17 cells and IFNY-producing Th1 cells in $\mathrm{CD}^{+} \mathrm{CD}^{+} \mathrm{T}$ cells of splenocytes and colonic LPMCS isolated from WT and mPGES-1 ${ }^{-1-}$ mice with colitis. Colonic LPMCs were pooled from 4 mice in each experiment on day 7 after the start of exposure to $1 \%$ DSS and analyzed by FCM, as described in the Methods $(n=5)$. B The ratio and the number of IL-17A $A^{+}$and IFNY ${ }^{+}$cells in $\mathrm{CD}^{+} \mathrm{CD}^{+} \mathrm{T}$ cells of colonic LPMCs on day 7 after the start of exposure to $1 \%$ DSS $(n=5)$. ${ }^{*} P<0.05 \mathrm{vs} \mathrm{WT;} t$ test 
A

LPMCs (Gated on $\mathrm{CD}^{+} \mathrm{CD}^{+}$)

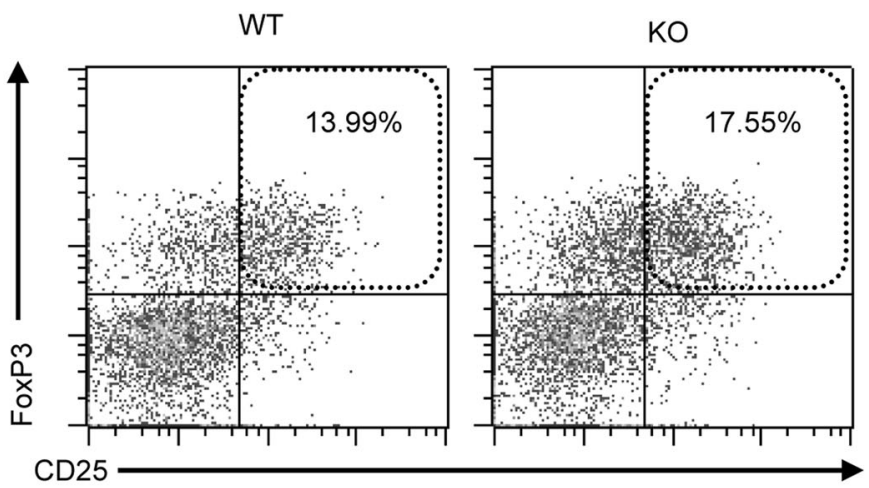

B
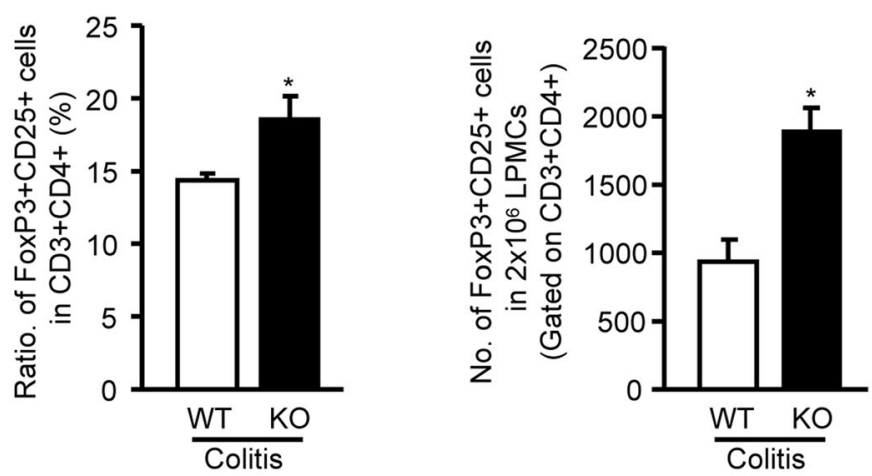

C

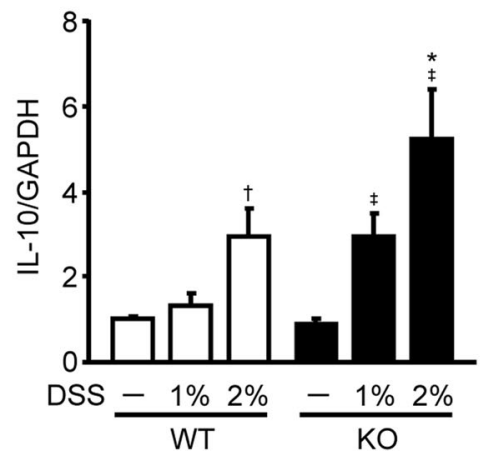

Fig. 8 Effect of mPGES-1 gene deletion on the generation of Tregs in DSS-induced colitis. A Representative FCM plot of FoxP3 ${ }^{+} \mathrm{CD} 25^{+}$Tregs in $\mathrm{CD}^{+} \mathrm{CD}^{+} \mathrm{T}$ cells of colonic LPMCs, isolated from WT and $\mathrm{mPGES}-1^{-1-}$ mice with colitis. Colonic LPMCs were pooled from 4 mice in each experiment on day 7 after the start of exposure to $1 \%$ DSS and subjected to FCM analysis, as described in the Methods $(n=5)$. B The ratio and the number of FoxP3 ${ }^{+} \mathrm{CD} 25^{+}$cells in $\mathrm{CD}^{+}{ }^{+} \mathrm{CD} 4^{+} \mathrm{T}$ cells of colonic LPMCs on day 7 after the start of exposure to $1 \%$ DSS $(n=5)$. C Expression of mRNA for IL-10 in the colon from mice treated or not treated with the indicated dose of DSS for 7 days was analyzed by real-time RT-PCR. Levels of mRNA expression are shown as the fold induction relative to the expression in WT without DSS administration (assigned the value "1"). ${ }^{*} P<$ 0.05 vs WT within each day, ${ }^{\dagger} P<0.05$ vs non-DSS-treated WT mice, and ${ }^{\ddagger} P<0.05$ vs non-DSS-treated KO mice; 2-way ANOVA followed by Tukey multiple comparison test ( $n=7$ to 12 )

known to be major macrophage cytokines, were significantly higher in mPGES-1 ${ }^{-1-}$ mice than in WT mice under either the GK1.5 or LTF2 treatment during DSS- induced colitis. In addition, the colonic expression levels of TNF $\alpha$ did not differ between WT and mPGES-1 ${ }^{-1-}$ mice after either the GK1.5 or LTF2 treatment. 


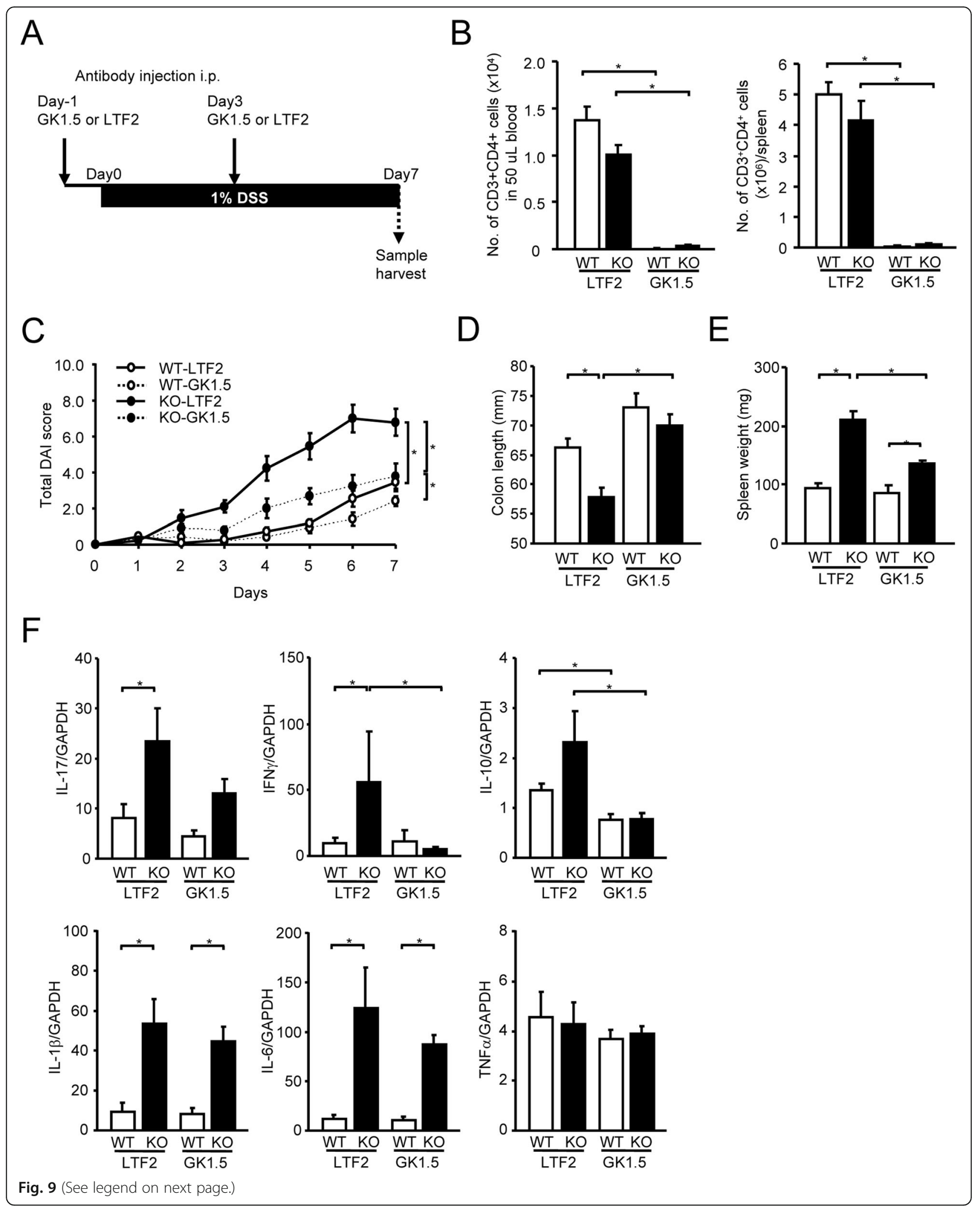


(See figure on previous page.)

Fig. 9 Effect of CD4 positive T cell depletion on the exacerbated DSS-induced colitis in mPGES-1 ${ }^{-1-}$ mice. A Schematic representation of the experimental plan. B The efficacy of in vivo $\mathrm{CD}^{+} \mathrm{T}$ cell depletion was confirmed by flow cytometry analysis of T cell population in the peripheral blood and spleen ( $n=9$ to 11). C Time course of change in total disease activity index (DAl) score of WT and mPGES- $1^{-1-}$ mice after indicated days of exposure to $1 \%$ DSS ( $n=9$ to 11). On day 7 after the start of exposure to $1 \%$ DSS, the length of the colon (D) and weight of the spleen (E) were measured as indirect markers of inflammation ( $n=9$ to 11$)$. F Expressions of mRNA for IL-17A, IFNy, IL-10, IL-1 $\beta$, IL-6, and TNFa in colon from mice treated with 1\% DSS for 7 days were analyzed by real-time RT-PCR ( $n=9$ to 11). Levels of mRNA expression are shown as the fold induction relative to the expression in WT mice without DSS administration (assigned the value "1"). ${ }^{*} P<0.05 ; 2$-way ANOVA followed by Tukey multiple comparison test

\section{Analysis of apoptosis in $\mathrm{mPGES}-1^{-1-}$ colons}

In situ apoptosis analysis revealed that apoptotic cells were basally detectable in the colon from mPGES-1 ${ }^{-/-}$ mice to the same extent as in the colon from WT mice. (Fig. 10A and B). After DSS administration, the number of apoptotic cells significantly increased in both WT and
mPGES-1 ${ }^{-/-}$mice. mPGES-1 deficiency did not affect the number of apoptotic cells in the colon not only in colitis but also in the healthy condition. In both WT and mPGES-1 ${ }^{-/-}$colon, mRNA expression of anti-apoptotic factor $\mathrm{Bcl} 2$ was significantly decreased by DSS, while mRNA expression of apoptotic marker Bak was

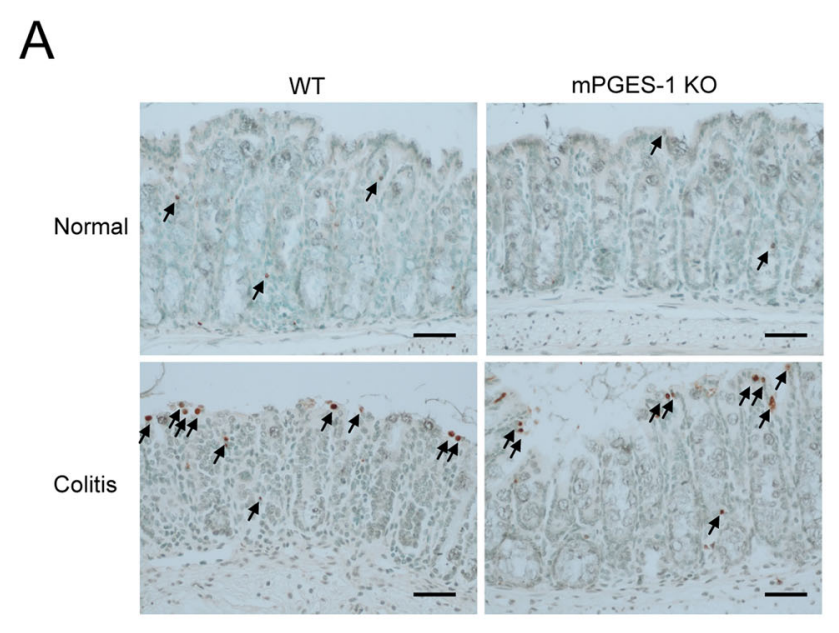

B

C
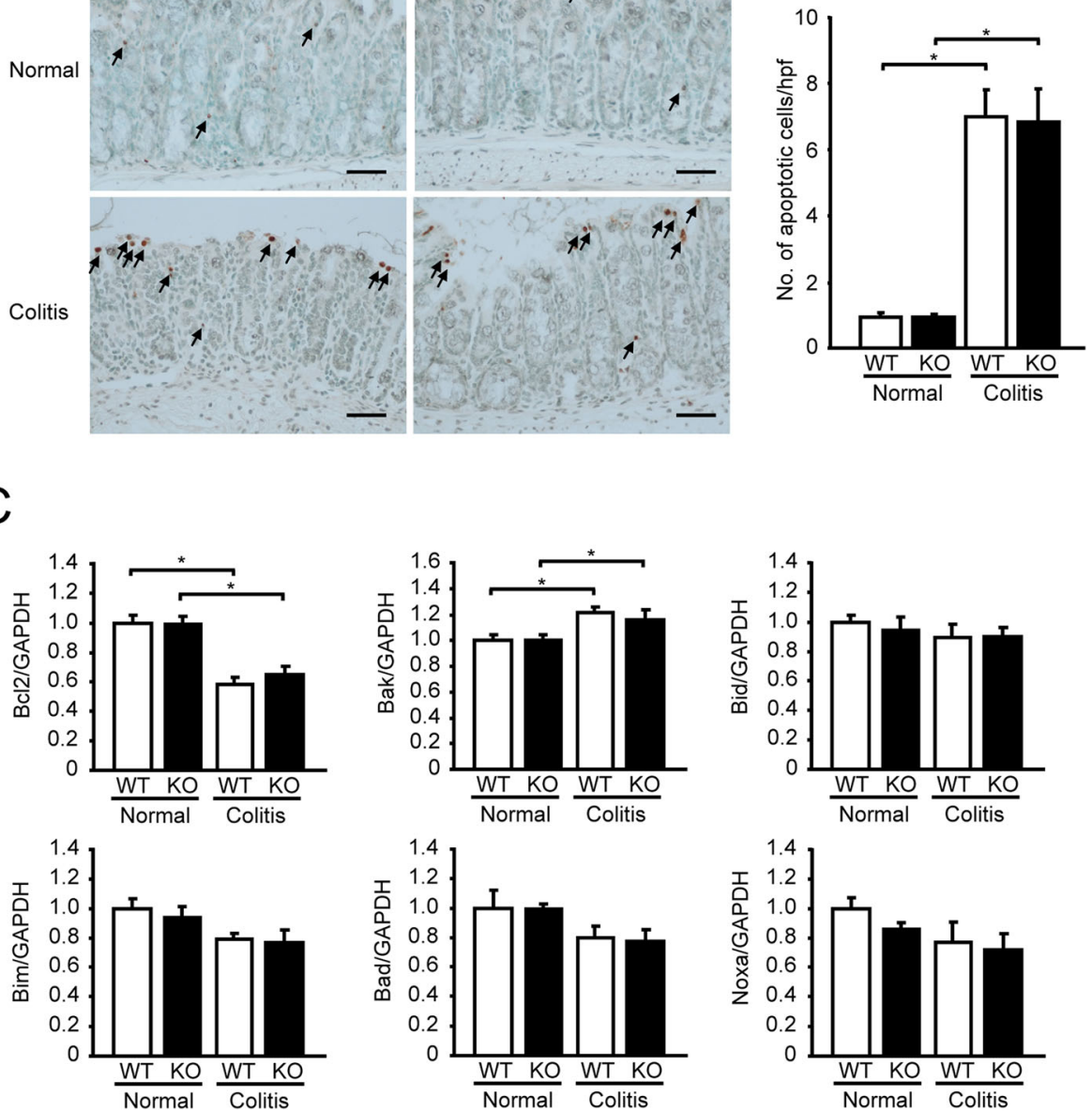

Fig. 10 Analysis of apoptosis in $\mathrm{mPGES}-1^{-/-}$colons. A Representative images of Swiss-roll colon sections on day 7 after the start of exposure to $1 \%$ DSS. Arrows indicate apoptotic cells. Scale bar, $50 \mu \mathrm{m}$. B Quantification of apoptotic cells in colon $(n=5)$. C mRNA expressions of an antiapoptotic factor Bcl2 and apoptotic markers, Bak, Bid, Bim, Bad, and Noxa, in colon from mice treated with 1\% DSS for 7 days were analyzed by real-time RT-PCR ( $n=7$ to 10). Levels of mRNA expression are shown as the fold induction relative to the expression in WT mice without DSS administration (assigned the value "1"). ${ }^{*} P<0.05 ;$ 2-way ANOVA followed by Tukey multiple comparison test 
significantly increased. These expressions were correlated well with the increased number of apoptotic cells observed after DSS administration in both WT and mPGES- $1^{-1-}$ mice. The colonic expressions of other apoptotic markers, Bid, Bim, Bad, and Noxa, were not changed by DSS treatment in either the WT or mPGES$1^{-/-}$mice.

\section{Discussion}

The present study demonstrates that mPGES-1 plays an important role in the pathogenesis of DSS-induced colitis by showing that genetic deletion of mPGES-1 resulted in greater inflammatory responses, including multiple colitis parameters and histologically characteristic features of colitis. We also show marked facilitation of colonic Th17 and Th1 immunity under mPGES-1 deficiency. Furthermore, our findings imply the possible potential for mPGES-1 as a pathogenic factor of colitis by suppressing anti-colitis activity mediated by Tregs.

mPGES-1 deficiency enhanced the severity of colitis, with massive weight loss, diarrhea, intestinal bleeding, severe epithelial damage, and infiltration of inflammatory cells after exposure to low-dose DSS, which caused only mild colonic injury in WT mice. A previous study reported that mPGES-1 genetic deletion enhanced colonic ulceration and caused higher mortality during colitis induced by a relatively high dose of DSS [31]. In another report, the fecal blood score was higher in mPGES- $1^{-1-}$ mice than in WT mice when mice were treated with a low molecular weight of high-dose DSS [30]. These studies partly support the findings of our study that mPGES-1 has a protective role during colitis. In a previous study on upstream COX isozymes, mice lacking COX-2 (COX-2 ${ }^{-/-}$mice) were more susceptible to DSS-induced colitis than those lacking COX-1 (COX$1^{-/-}$mice); however, after exposure to DSS, COX $-1^{-1-}$ mice were more susceptible to symptoms of colitis than WT mice [52], suggesting that both COX-1 and COX-2 are involved in colon injury. Pharmacological inhibition of both COX-1 and COX-2 and the resultant decrease in the level of intestinal $\mathrm{PGE}_{2}$ have also been shown to be responsible for NSAID-dependent exacerbation of DSSinduced colitis [53]. Furthermore, in a study on mice lacking EP receptor subtypes $\left(\mathrm{EP}^{-/-}\right.$mice), it has been clearly demonstrated that only $\mathrm{EP}_{4}{ }^{-/-}$mice developed severe colitis with DSS, while the colitis parameters of $\mathrm{EP}_{1}{ }^{-/-}, \mathrm{EP}_{2}{ }^{-/-}$, and $\mathrm{EP}_{3}^{-/-}$mice were similar to those of control WT mice [13]. Similarly, a number of studies with an EP antagonist/antagonist further support the essential role of $\mathrm{PGE}_{2}$ in DSS-induced colitis and that it mediates its effects via $\mathrm{EP}_{4}$ signaling $[13,54,55]$. Our findings, together with those of earlier studies, suggest that the COX/mPGES-1/PGE 2 axis could play a pivotal role in DSS-induced colitis predominantly via $\mathrm{EP}_{4}$ signaling.

One of the important findings of our study is that a lack of mPGES-1 enhanced the colonic induction of COX-2 in response to DSS. In addition, mPGES-1 deficiency altered $\mathrm{EP}_{2}$ and $\mathrm{EP}_{3}$ expression after DSS administration. These results indicate that $\mathrm{mPGES}-1$ and its associated $\mathrm{PGE}_{2}$ regulate the expression of their upstream enzymes and downstream receptors in a feedback loop. We also demonstrated that induction of mPGES-1 is essential for the marked increase of colonic $\mathrm{PGE}_{2}$ production during colitis. This finding is consistent with similar findings of the response of other tissues and cell types, such as macrophages, embryo fibroblasts, dendritic cells, and splenocytes, to various inflammatory stimuli [23, 25, 56-58]. Regarding upstream COX, previous studies showed that colonic $\mathrm{PGE}_{2}$ production is significantly lower in DSS-treated COX-2 ${ }^{-/-}$mice than in both DSS-treated WT and DSS-treated COX-1 $1^{-1-}$ mice, indicating the predominant contribution of COX-2 to colonic $\mathrm{PGE}_{2}$ synthesis during colitis [52]. Thus, coordinated induction of COX-2 and mPGES- 1 would be accompanied by an increase in $\mathrm{PGE}_{2}$ levels during severe colitis. Interestingly, the colonic level of $\mathrm{PGE}_{2}$ was shown to decrease after treatment with a selective COX1 inhibitor [53], suggesting that COX-1 also partly contributes to $\mathrm{PGE}_{2}$ production during colitis. Additionally, colonic tissues of $\mathrm{COX}_{-1}^{-1-}$ mice contain almost undetectable basal levels of $\mathrm{PGE}_{2}$, indicating that basal $\mathrm{PGE}_{2}$ production is largely dependent on $\mathrm{COX}-1$ in the colon [52]. In the present study, we also saw evidence for a significant reduction in basal $\mathrm{PGE}_{2}$ production in the absence of mPGES-1 in the colon. mPGES-1 may be differentially contributing to $\mathrm{PGE}_{2}$ production, which might be the result of functional coupling to upstream COX-1.

Noteworthy is that we detected increased production of colonic $\mathrm{PGD}_{2}$ in $\mathrm{mPGES}-1^{-1-}$ mice, which seemed to be due to shunting of PG precursors down the $\mathrm{PGD}_{2}$ synthetic pathway in the absence of mPGES-1. We also detected enhanced colonic COX-2 expression as a result of mPGES-1 deletion. These results suggest that an elevation of COX-2 and the resultant increase in the availability of $\mathrm{PGH}_{2}$-as the common substrate for the generation of prostanoid-account for the increased levels of $\mathrm{PGD}_{2}$ observed in mPGES-1 ${ }^{-/-}$mice. These results are further supported by our previous study with $m P G E S-1^{-/}$dendritic cells, which showed shunting toward $\mathrm{PGD}_{2}$ production [58]. Because a number of studies demonstrated the anti-colitis activities of $\mathrm{PGD}_{2}$ and its biosynthetic PGD synthases in both experimental colitis and human IBD $[16,46,59,60]$, we propose that the increased $\mathrm{PGD}_{2}$ may suppress colitis in the absence of mPGES-1. However, our results showed that lack of 
mPGES-1 conversely exacerbates colitis and suppresses $\mathrm{PGE}_{2}$ production, even though levels of anti-colitis $\mathrm{PGD}_{2}$ increase; these findings suggest that during colitis, mPGES-1-driven $\mathrm{PGE}_{2}$ plays a greater role than $\mathrm{PGD}_{2}$ as an anti-colitis prostanoid.

Our study demonstrated for the first time that mPGES-1 is overexpressed in the colonic mucosal epithelium and infiltrated inflammatory cells in underlying connective tissues and the LP in the colon during DSSinduced colitis. In human IBD including both ulcerative colitis and Crohn's disease, mPGES-1 was also found to be expressed in the epithelial and inflammatory cells that surround the damaged crypt in the colon during active colitis [28]; this result strongly supports our finding of colonic localization of mPGES-1, which we propose to be responsible for elevated colonic $\mathrm{PGE}_{2}$ production during colitis. A number of reports indicated the tissue localization of upstream COX isozymes in mice models of colitis [61,62], and the pattern in human IBD was found to be similar $[16,63]$. The reported localizations of COX isozymes are consistent with the mPGES-1 expression observed in the present study. COX-1 is constitutively expressed in the crypt epithelium and LPMCs in both normal and inflamed colon [61]. In contrast, COX2 is undetectable in normal colon, but during DSSinduced colitis, it is elevated in epithelial cells in the colon [62] and in a number of LPMCs [61]. Notably, a study demonstrated that COX-2 is required in myeloid cells and endothelial cells for protection against DSSinduced colitis, but not in epithelial cells [64]. mPGES-1 might be differently coupled with COX-1 and COX-2, depending on the expression pattern and its localization in tissues and cell-specific manner. A variety of inflammatory and immune cells may be able to express mPGES-1 within the colon tissues and may be differently responsible for $\mathrm{PGE}_{2}$ production. In the present study, we identified $\mathrm{CD}^{+}$cells and $\mathrm{CD} 11 \mathrm{~b}^{+}$cells as the component of inflammatory cells expressing mPGES-1 in the underlying connective tissues and colonic LP. In fact, proinflammatory stimuli-activated macrophages and dendritic cells are able to express mPGES-1, resulting in abundant $\mathrm{PGE}_{2}$ production in vitro $[22,58]$. Activated $\mathrm{CD} 4^{+} \mathrm{T}$ cells also express mPGES- 1 and produce $\mathrm{PGE}_{2}$ in an mPGES-1-dependent fashion [27]. It has been shown that mPGES-1 is detected with COX-2 to some extent in the colonic lamia propria in $\mathrm{T}$ celldriven colitis induced by adoptive transfer of $\mathrm{CD}^{+}$effector $\mathrm{T}$ cells in mice [65]. Additionally, the study revealed that $\mathrm{T}$ cells lacking $\mathrm{mPGES}-1$-dependent $\mathrm{PGE}_{2}$ production have reduced colitogenicity, whereas mPGES-1 deficiency in non-lymphoid cells facilitates $\mathrm{T}$ cell-driven colitis [65]; the authors interpreted their findings as suggesting that the effects of $\mathrm{PGE}_{2}$ derived from $\mathrm{T}$ cells differ from those of $\mathrm{PGE}_{2}$ derived from other non-lymphoid cells. Further, a previous study investigated DSS-associated colon tumorigenesis in $\mathrm{Apc}^{\Delta 14 /+}$ mice, a mouse model of familial adenomatous polyposis and reported that mPGES-1 is abundantly expressed in infiltrating cells of colonic ulcerated sites and that some of the mPGES-1-expressing cells were vimentin-positive mesenchymal/fibroblast cells [66]. The group also demonstrated the role of mPGES-1 in the early inflammatory phase of developing colonic carcinogenesis in the $\mathrm{Apc}^{\Delta 14 /+}$ mice. Future studies in mice with tissue-specific deletion of mPGES-1 may further clarify the intrinsic action of mPGES-1 in distinct cell types in the colon during colitis.

In mice with DSS-induced colitis, we further investigated the role of mPGES-1 in pathogenic immunity in IBD. A previous study reported that mice with DSSinduced colitis show a similar expression profile of cytokines and similar histological changes to those observed in human IBD [67]. DSS treatment induces Th17 cytokines (such as IL-17A) and Th1 cytokines (including IFNY and IL-2) in the colon, and these cytokines are essential for developing colitis [67-69]. In the present study, we demonstrated for the first time that lack of mPGES-1 facilitates the colonic expression of Th17 and Th1 cytokines in DSS-induced colitis. Our study found a significant increase in colonic expression of IL-17A, as well as IFN $\gamma$ and IL-2, during colitis in mPGES-1 ${ }^{-1-}$ mice compared with WT mice. In addition, we showed that the colonic expressions of IL- $1 \beta$, IL- 6 , and TGF $\beta 1$, which are essential cytokines for Th17 cell expansion and differentiation [47-49], were greater in $\mathrm{mPGES}-1^{-1-}$ mice. Indeed, we found that IL-17A-producing Th17 cells within colonic LP increase in the absence of mPGES-1, suggesting that during colitis, a mPGES-1dependent mechanism regulates Th17 differentiation and expansion and also lymphocyte infiltration into the inflammatory sites. The present study also demonstrated an increase in colonic IFN $\gamma$-producing Th1 cells in colonic LP and an elevated expression of IL-12p35, a subunit of IL-12 that differentially expands Th1 cells. In addition, we found that $\mathrm{L}-17^{+} \mathrm{IFN} \gamma^{+}$double positive cells in colonic LP are increased in $\mathrm{mPGES}-1^{-1-}$ mice than in WT mice. A previous study showed that IFN $\gamma^{+} \mathrm{IL}$ $17^{+}$coproducing $\mathrm{CD} 4^{+} \mathrm{T}$ cells as a pathogenic Th17 cells are specifically enriched in the inflamed mucosal tissue of IBD patients but not healthy individuals [70].These enhanced colonic Th17 and Th1 immune responses observed in mPGES-1 ${ }^{-/-}$mice seems to be associated with the abnormalities consistent with the colitis.

IL-23 is one of the prominent targets of recent biological therapies for the treatment of IBD, as well as several autoimmune diseases. IL-23 has been shown to facilitate the expansion and maintenance of Th17 cells, and the IL-17/IL-23 axis has been shown to be relevant 
in IBD pathogenesis [50]. A previous study demonstrated that $\mathrm{PGE}_{2}-\mathrm{EP}_{4}$ signaling, in combination with IL23 , regulates Th17 cell expansion in vitro [71, 72]. However, the present study found that the colonic expression levels of IL-23 components were similar in both WT and $\mathrm{mPGES}-\mathrm{1}^{-1-}$ mice, suggesting that during colitis facilitation of the Th17 immune response in the absence of mPGES-1 might be independent of IL-23.

Previous studies focused on the expression of IL- $1 \beta$ and TNF $\alpha$ as promising proinflammatory cytokines in the absence of mPGES-1 during colitis [30, 31]. We also confirmed that during colitis, a lack of mPGES-1 facilities increased expression levels of IL- $1 \beta$, in addition to IL-6. On the other hand, in our study, the differences in the expression levels of TNF $\alpha$ between WT and mPGES- $1^{-1-}$ mice during colitis did not reach statistical significance, a finding apparently in contradiction to published data indicating upregulation of TNF $\alpha$ expression in the absence of mPGES-1 in DSS-induced colitis [30]. Previous reports have documented differences in DSS-induced colitis related to the source of DSS [73, 74]. Therefore, the disparate results obtained from our study and the report [30] could be explained by the fact that they performed their studies with low-molecularweight DSS, whereas we used high-molecular-weight, colitis-grade DSS.

FoxP $3^{+} \mathrm{CD} 25^{+}$Tregs have been conclusively shown to suppress mucosal inflammation associated with murine colitis [75-77]. In the present study, during DSSinduced colitis, immune suppressive $\mathrm{FoxP}^{+} \mathrm{CD} 25^{+}$ Tregs within colonic LP were markedly increased in mPGES-1 $1^{-1-}$ mice compared with WT mice. In addition, mPGES-1 $1^{-1-}$ mice had a higher expression of colonic IL10 , which is well known as an anti-colitis cytokine produced by Tregs and other immune cells. These results suggest that mPGES-1 may act as a pathogenic factor of colitis by negatively regulating immunosuppression mediated by both Tregs and IL-10. The reason why Tregs increase during severe colitis in the absence of mPGES-1 is unknown, but a similar increase of FoxP3 ${ }^{+}$Tregs was observed at the site of intestinal inflammation in patients with IBD $[78,79]$, even though the Tregs retained potent suppressive activity [80], implying a possible countereffect of $\mathrm{FoxP}^{+}$Tregs against excessive abnormal immune responses associated with IBD. To date, autocrine and paracrine effects of $\mathrm{PGE}_{2}$ have been shown to be involved in the induction and function of $\mathrm{FoxP}^{+} \mathrm{CD} 25^{+}$ Tregs. FoxP $3^{+} \mathrm{CD} 25^{+}$Tregs express COX- 2 and suppress effector $\mathrm{T}$ cells by a $\mathrm{PGE}_{2}$-dependent mechanism in vitro [81]. However, in a colitis model induced by adoptive transfer of $\mathrm{T}$ cells, non-lymphoid mPGES-1dependent $\mathrm{PGE}_{2}$ facilitated the expansion of FoxP3 ${ }^{+}$ Tregs and contributed to the resultant suppression of colonic inflammation, whereas $\mathrm{CD}^{+}$effector $\mathrm{T}$ cells expressing mPGES-1 had the potential for developing colitis [65]. In addition, it has been reported that $\mathrm{PGE}_{2}$ mediated immunosuppressive mechanisms during colitis were independent on the function of Tregs [82]. Thus, the different roles of $\mathrm{mPGES}-1$-associated $\mathrm{PGE}_{2}$ in regulating the differentiation and function of Tregs in human IBD remain elusive.

A previous study reported that DSS-induced colitis can be induced in mice depleted of $\mathrm{CD}_{4}^{+}$helper $\mathrm{T}$ cell by the treatment with $\mathrm{CD} 4$ monoclonal antibody [83]. Alternatively, another report demonstrated with $\mathrm{CD} 4^{+} \mathrm{T}$ cell depletion that $\mathrm{T}$ cells of $\mathrm{CD} 4^{+}$but not $\mathrm{CD} 8^{+}$phenotype are responsible for the modulation of DSS-induced colitis [84]. In our study, CD4 $4^{+} \mathrm{T}$ cell depletion did not show obvious effect on DSS-induced colitis in WT mice, but it effectively reduced symptoms of colitis as well as colonic expression of Th17 and Th1 cytokines in mPGES- $1^{-/-}$mice, suggesting the requirement of $\mathrm{CD} 4^{+}$ $\mathrm{T}$ cells in the exacerbation of DSS-induced colitis under mPGES-1 deficiency. Interestingly, even though the $\mathrm{CD}^{+} \mathrm{T}$ cell depletion was effective in $\mathrm{mPGES}-1^{-1-}$ mice, a part of symptoms were still remained to be significantly different when compared with $\mathrm{CD} 4^{+} \mathrm{T}$ cell-depleted WT mice, suggesting that during colitis, $\mathrm{CD} 4^{+} \mathrm{T}$ cell-independent events also play a role to some extent in the absence of mPGES-1. In the present study, colonic expressions of IL-1 $\beta$ and IL-6, major macrophagerelated proinflammatory cytokines relevant to IBD, were still exacerbated in mPGES- $1^{-1-}$ mice under the CD $4^{+} \mathrm{T}$ cell depletion during colitis. It was previously reported that $\mathrm{PGE}_{2}-\mathrm{EP}_{4}$ signaling modulates macrophage activation and alters the profile of macrophage cytokines [85, 86], suggesting that macrophages in the colon of mPGES $-1^{-/-}$mice may be excessively activated. The details of events independent of $\mathrm{CD} 4^{+} \mathrm{T}$ cells remain to be studied.

A recent study has clearly demonstrated that $\mathrm{PGE}_{2^{-}}$ $\mathrm{EP}_{4}$ system plays an important role in maintaining homeostasis in the colon. The study indicated that epithelial-specific deletion of $\mathrm{EP}_{4}$ leads to exacerbation of DSS-induced colitis, which is associated with enhancement of apoptosis in colonic epithelial cells [15]. The present study showed that $\mathrm{mPGES}-1^{-1-}$ mice exhibited exacerbation of DSS-induced colitis, but mPGES-1 deficiency did not affect the number of apoptotic cells in the colon not only in the healthy condition but also in colitis. In fact, a low level of $\mathrm{PGE}_{2}$ was still detectable in the mice without mPGES-1, suggesting that cPGES and other PGES isozymes other than mPGES-1 may contribute to $\mathrm{PGE}_{2}$ production to maintain colon homeostasis in colon.

The present study clearly demonstrated that mPGES-1 is the main PGE synthase responsible for intestinal $\mathrm{PGE}_{2}$ production and that $\mathrm{mPGES}-1-$ associated $\mathrm{PGE}_{2}$ plays a 
protective role in IBD, partly by regulating immune systems associated with $\mathrm{CD} 4^{+}$helper T cells. Th17/Th1 immune system of the intestinal tract may be a possible representative to explain the mechanism of immunomodulation by $\mathrm{CD}^{+}$helper $\mathrm{T}$ cells in the absence of mPGES-1. mPGES-1 is a promising candidate for drug development because mPGES-1 inhibition could specifically diminish the elevated $\mathrm{PGE}_{2}$ production associated with various autoimmune inflammatory diseases. However, in IBD, the protective effect mediated by mPGES1-driven $\mathrm{PGE}_{2}$ appears to be indispensable for preventing the hyperactivation of the pathogenic $\mathrm{T}$ cell immune response and resultant intestinal inflammation. Thus, the present study also provides potentially important information on the possible disadvantageous effect of pharmacological mPGES-1 inhibition in patients with IBD. To investigate the therapeutic efficacy and safety of mPGES-1 inhibitors, future studies need to assess whether mPGES-1 inhibitors can mimic the results observed in $\mathrm{mPGES}-1^{-/-}$mice and how their effects differ from those of traditional COX inhibitors.

\section{Conclusions}

mPGES-1 is the main enzyme responsible for colonic $\mathrm{PGE}_{2}$ production, and deficiency of mPGES-1 facilitates the development of colitis by affecting the development of colonic $\mathrm{T}$ cell-mediated immunity. mPGES-1 might therefore impact both the intestinal inflammation and $\mathrm{T}$ cell-mediated immunity associated with IBD.

\begin{abstract}
Abbreviations
IBD: Inflammatory bowel disease; Th: T-helper; Tregs: Regulatory T cells; PG: Prostaglandin; COX: Cyclooxygenase; PGES: PGE synthase: CPGES: Cytosolic PGES; MPGES-1: Microsomal PGES-1; NSAIDs: Nonsteroidal anti-inflammatory drugs; mPGES-1 ${ }^{-/-}$mice: Mice lacking mPGES-1;

DSS: Dextran sodium sulfate; WT: Wild-type; PCR: Polymerase chain reaction; DAl: Disease activity index; HGB: Hemoglobin; HCT: Hematocrit;

H\&E: Hematoxylin and eosin; FITC: Fluorescein isothiocyanate; GAPD

H: Glyceraldehyde 3-phosphate dehydrogenase; LPMCs: Lamina propria mononuclear cells; FCM: Flow cytometry; IFNy: Interferon- $\gamma$; LP: Lamina propria; $\mathrm{COX}-2^{-/-}$mice: Mice lacking COX-2; $\mathrm{COX}_{-1^{-/-}}$mice: Mice lacking $\mathrm{COX}-1 ; \mathrm{EP}^{-1-}$ mice: Mice lacking EP receptor subtypes
\end{abstract}

\section{Supplementary Information}

The online version contains supplementary material available at https://doi. org/10.1186/s41232-021-00188-1

Additional file 1: Table S1. The number of cell subset in splenocytes from mice treated with or without 1\% DSS for 7 days.

Additional file 2: Figure S1. Change of water and food uptake in DSSinduced colitis. Weekly water uptake of mPGES-1-/- mice was significantly decreased by $1 \%$ DSS administration, while no significant difference was observed in comparison with WT mice. MPGES-1-/- mice showed a trend towards lower uptake than WT mice. A significant decrease in food uptake was observed in mPGES-1-/- mice during DSS administration over 7 days, indicating severe symptoms of colitis in mPGES$1-/-$ mice. ${ }^{*} \mathrm{P}<0.05$; 2-way ANOVA followed by Tukey multiple comparison test ( $n=3$ to 5). Figure S2. In vivo depletion of CD4+ T cells by anti-CD4 (clone GK1.5) monoclonal antibody. (A) Schematic representation of the experimental plan (A). Solid allows indicate time-point (days) at which intraperitoneal injection of the antibody were performed. The efficacy of CD4+ T cell depletion was confirmed by FCM analysis of T cell population in the peripheral blood (B), spleen (C) and LPMCs (D). FCM analysis confirmed that anti-CD4 antibody treatment effectively reduced the number of $\mathrm{CD} 3+\mathrm{CD} 4+\mathrm{T}$ cells but not $\mathrm{CD}^{+} \mathrm{CD}^{+} \mathrm{T}$ cells in the peripheral blood, spleen and LPMCs of the treated mice compared to the control mice. ${ }^{*} \mathrm{P}<0.05$ vs. control; $t$ test $(n=3)$.

\section{Acknowledgments}

We thank Prof. Hideki Amano (Kitasato University) for support in evaluating anemia, Dr. Rei Kawashima (Kitasato University) for helpful advice on isolating LPMC, Prof. Makoto Ohbu (Kitasato University) and Prof. Hiroyuki Takahashi (Kitasato University) for support in histological assessments, Prof. Toshihiko Kawamura (Kitasato University) for support on FCM utilization, Prof. Naohito Ishii (Kitasato University) for valuable advice and support, Prof. Yuichi Kadoya (Kitasato University) for support on fluorescence microscope utilization and Dr. Sachiko Oh-ishi (Prof. emerita, Kitasato University) for reviewing the manuscript.

\section{Authors' contributions}

FK, HKi, and TI conceived and presented idea. FK, HS, and MK designed and carried out the experiment. YH and SM carried out the experiments. FK, HS, $\mathrm{YH}$, and MK analyzed the data. FK, HS, YH, HKa, MK, MN, SM, HKi, and TI contributed to the interpretation of the results. FK and HKa have a major contribution in drafting the manuscript. MK, MN, SM, YI, KY, FU, HKi, and TI reviewed and edited the manuscript. The authors read and approved the final manuscript.

\section{Funding}

This work was supported by a Grant-in-Aid for a Research Project from Kitasato University Graduate School of Medical Sciences (Integrative Research Program 2017-2018, Student Research Program 2017-2018), the Regenerative Medicine and Cell Design Research Facility (Research Program 2018), and Kitasato University School of Allied Health Sciences (Research Project 2015-1033, 2016-1011, 2017-1019). This study was also partly supported by JSPS KAKENHI (Grant Number 21 K06603).

\section{Availability of data and materials}

Data generated or analyzed during this study are included in this published article and its supplementary information files.

\section{Declarations}

Ethics approval and consent to participate

All animal experiments were approved by the Animal Research and Ethics Committee of Kitasato University (Approval number Ei-ken 19-12), and all experiments in $\mathrm{mPGES}^{-1^{-1}}$ mice were approved by the Safety Committee for Recombinant DNA Experiments of Kitasato University (Approval number 3593).

\section{Consent for publication}

Not applicable

\section{Competing interests}

The authors declare that they have no competing interest regarding the publication of this paper.

\section{Author details}

${ }^{1}$ Department of Pharmacology, Kitasato University School of Allied Health Sciences, 1-15-1 Kitasato, Sagamihara 252-0373, Japan. ${ }^{2}$ Department of Regulation Biochemistry, Kitasato University Graduate School of Medical Sciences, 1-15-1 Kitasato, Sagamihara 252-0373, Japan. ${ }^{3}$ Regenerative Medicine and Cell Design Research Facility, 1-15-1 Kitasato, Sagamihara 252-0373, Japan. ${ }^{4}$ Department of Pharmacology, Asahikawa Medical University, 2-1-1-1 Midorigaoka higashi, Asahikawa 078-8510, Japan. ${ }^{5}$ Division of Clinical Immunology, Graduate School of Medical Sciences, Kitasato University, 1-15-1 Kitasato, Minami-ku, Sagamihara 252-0373, Japan. ${ }^{6}$ Department of Environmental Microbiology, Kitasato University Graduate School of Medical Sciences, 1-15-1 Kitasato, Sagamihara 252-0373, Japan. 
Received: 27 August 2021 Accepted: 7 December 2021

\section{Published online: 04 January 2022}

\section{References}

1. Ananthakrishnan AN. Epidemiology and risk factors for IBD. Nat Rev Gastroenterol Hepatol. 2015;12(4):205-17. https://doi.org/10.1038/nrgastro.2 015.34.

2. Guan Q. A comprehensive review and update on the pathogenesis of inflammatory bowel disease. J Immunol Res. 2019;2019:1-16. https://doi. org/10.1155/2019/7247238

3. Friedrich M, Pohin M, Powrie F. Cytokine networks in the pathophysiology of inflammatory bowel disease. Immunity. 2019;50(4):992-1006. https://doi. org/10.1016/j.immuni.2019.03.017.

4. Lee SH, Kwon JE, Cho ML. Immunological pathogenesis of inflammatory bowel disease. Intest Res. 2018;16(1):26-42. https://doi.org/10.5217/ir.2018.1 6.1.26.

5. Kojima F, Kapoor M, Kawai S, Crofford LJ. New insights into eicosanoid biosynthetic pathways: implications for arthritis. Expert Rev Clin Immunol. 2006;2(2):277-91. https://doi.org/10.1586/1744666X.2.2.277.

6. Kojima F, Matnani RG, Kawai S, Ushikubi F, Crofford L. Potential roles of microsomal prostaglandin E synthase-1 in rheumatoid arthritis. Inflamm Regen. 2011;31(2):157-66. https://doi.org/10.2492/inflammregen.31.157.

7. Jakobsson PJ, Thoren S, Morgenstern R, Samuelsson B. Identification of human prostaglandin E synthase: a microsomal, glutathione-dependent, inducible enzyme, constituting a potential novel drug target. Proc Natl Acad Sci U S A. 1999;96(13):7220-5. https://doi.org/10.1073/pnas.96.13.7220.

8. Murakami M, Naraba H, Tanioka T, Semmyo N, Nakatani Y, Kojima F, et al. Regulation of prostaglandin E2 biosynthesis by inducible membraneassociated prostaglandin E2 synthase that acts in concert with cyclooxygenase-2. J Biol Chem. 2000;275(42):32783-92. https://doi.org/10.1 074/jbc.M003505200

9. Murakami M, Nakashima K, Kamei D, Masuda S, Ishikawa Y, Ishii T, et al. Cellular prostaglandin E2 production by membrane-bound prostaglandin E synthase-2 via both cyclooxygenases-1 and -2. J Biol Chem. 2003;278(39): 37937-47. https://doi.org/10.1074/jbc.M305108200.

10. Tanioka T, Nakatani Y, Semmyo N, Murakami M, Kudo I. Molecular identification of cytosolic prostaglandin E2 synthase that is functionally coupled with cyclooxygenase-1 in immediate prostaglandin E2 biosynthesis. J Biol Chem. 2000;275(42):32775-82. https://doi.org/10.1074/jbc.M0035042 00 .

11. Sharon P, Ligumsky M, Rachmilewitz D, Zor U. Role of prostaglandins in ulcerative colitis. Enhanced production during active disease and inhibition by sulfasalazine. Gastroenterology. 1978;75(4):638-40. https://doi.org/10.101 6/S0016-5085(19)31672-5

12. Narumiya S, Sugimoto $Y$, Ushikubi F. Prostanoid receptors: structures, properties, and functions. Physiol Rev. 1999;79(4):1193-226. https://doi.org/1 0.1152/physrev.1999.79.4.1193.

13. Kabashima K, Saji T, Murata T, Nagamachi M, Matsuoka T, Segi E, et al. The prostaglandin receptor EP4 suppresses colitis, mucosal damage and CD4 cell activation in the gut. J Clin Invest. 2002;109(7):883-93. https://doi.org/1 $0.1172 / \mathrm{JCl} 14459$

14. Jiang GL, Nieves A, Im WB, Old DW, Dinh DT, Wheeler $L$. The prevention of colitis by E prostanoid receptor 4 agonist through enhancement of epithelium survival and regeneration. J Pharmacol Exp Ther. 2007;320(1):228. https://doi.org/10.1124/jpet.106.111146.

15. Matsumoto $Y$, Nakanishi Y, Yoshioka T, Yamaga $Y$, Masuda T, Fukunaga $Y$, et al. Epithelial EP4 plays an essential role in maintaining homeostasis in colon. Sci Rep. 2019;9(1):15244. https://doi.org/10.1038/s41598-019-51639-2.

16. Vong L, Ferraz JG, Panaccione R, Beck PL, Wallace JL. A pro-resolution mediator, prostaglandin $D(2)$, is specifically up-regulated in individuals in long-term remission from ulcerative colitis. Proc Natl Acad Sci U S A. 2010; 107(26):12023-7. https://doi.org/10.1073/pnas.1004982107.

17. Korelitz BI. Role of nonsteroidal anti-inflammatory drugs in exacerbation of inflammatory bowel disease. J Clin Gastroenterol. 2016;50(2):97-8. https:// doi.org/10.1097/MCG.0000000000000444.

18. Engblom D, Saha S, Engstrom L, Westman M, Audoly LP, Jakobsson PJ, et al. Microsomal prostaglandin E synthase-1 is the central switch during immune-induced pyresis. Nat Neurosci. 2003;6(11):1137-8. https://doi.org/1 $0.1038 / \mathrm{nn} 1137$.

19. Saha S, Engstrom L, Mackerlova L, Jakobsson PJ, Blomqvist A. Impaired febrile responses to immune challenge in mice deficient in microsomal prostaglandin E synthase-1. Am J Physiol Regul Integr Comp Physiol. 2005; 288(5):R1100-7. https://doi.org/10.1152/ajpregu.00872.2004.

20. Inada M, Matsumoto C, Uematsu S, Akira S, Miyaura C. Membrane-bound prostaglandin E synthase-1-mediated prostaglandin E2 production by osteoblast plays a critical role in lipopolysaccharide-induced bone loss associated with inflammation. J Immunol. 2006;177(3):1879-85. https://doi. org/10.4049/jimmunol.177.3.1879.

21. Trebino CE, Stock JL, Gibbons CP, Naiman BM, Wachtmann TS, Umland JP, et al. Impaired inflammatory and pain responses in mice lacking an inducible prostaglandin E synthase. Proc Natl Acad Sci U S A. 2003;100(15): 9044-9. https://doi.org/10.1073/pnas.1332766100.

22. Uematsu S, Matsumoto M, Takeda K, Akira S. Lipopolysaccharide-dependent prostaglandin $\mathrm{E}(2)$ production is regulated by the glutathione-dependent prostaglandin $\mathrm{E}(2)$ synthase gene induced by the Toll-like receptor 4/ MyD88/NF-IL6 pathway. J Immunol. 2002;168(11):5811-6. https://doi.org/1 0.4049/jimmunol.168.11.5811.

23. Kapoor M, Kojima F, Qian M, Yang L, Crofford L. Shunting of prostanoid biosynthesis in microsomal prostaglandin E synthase-1 null embryo fibroblasts: regulatory effects on inducible nitric oxide synthase expression and nitrite synthesis. Faseb J. 2006;20(13):2387-9. https://doi.org/10.1096/fj.06-6366fje.

24. Kapoor M, Kojima F, Qian M, Yang L, Crofford LJ. Microsomal prostaglandin E synthase-1 deficiency is associated with elevated peroxisome proliferatoractivated receptor gamma: regulation by prostaglandin $\mathrm{E} 2$ via the phosphatidylinositol 3-kinase and Akt pathway. J Biol Chem. 2007;282(8): 5356-66. https://doi.org/10.1074/jbc.M610153200.

25. Kojima F, Kapoor M, Yang L, Fleishaker EL, Ward MR, Monrad SU, et al. Defective generation of a humoral immune response is associated with a reduced incidence and severity of collagen-induced arthritis in microsomal prostaglandin E synthase-1 null mice. J Immunol. 2008;180(12):8361-8. https://doi.org/10.4049/jimmunol.180.12.8361.

26. Kojima F, Frolov A, Matnani R, Woodward JG, Crofford L. Reduced T celldependent humoral immune response in microsomal prostaglandin $\mathrm{E}$ synthase-1 null mice is mediated by nonhematopoietic cells. J Immunol. 2013;191(10):4979-88. https://doi.org/10.4049/jimmunol.1301942.

27. Maseda D, Johnson EM, Nyhoff LE, Baron B, Kojima F, Wilhelm AJ, et al. mPGES1-dependent prostaglandin E2 (PGE2) controls antigen-specific Th17 and Th1 responses by regulating $T$ autocrine and paracrine PGE2 production. J Immunol. 2018;200(2):725-36. https://doi.org/10.4049/ jimmunol.1601808.

28. Subbaramaiah K, Yoshimatsu K, Scherl E, Das KM, Glazier KD, Golijanin D, et al. Microsomal prostaglandin E synthase-1 is overexpressed in inflammatory bowel disease. Evidence for involvement of the transcription factor Egr-1. J Biol Chem. 2004;279(13):12647-58. https://doi.org/10.1074/jbc. M312972200.

29. Chassaing B, Aitken JD, Malleshappa M, Vijay-Kumar M. Dextran sulfate sodium (DSS)-induced colitis in mice. Curr Protoc Immunol. 2014;104(1):15. 25.1-15.25.14. https://doi.org/10.1002/0471142735.im1525s104.

30. Hara S, Kamei D, Sasaki Y, Tanemoto A, Nakatani Y, Murakami M. Prostaglandin E synthases: understanding their pathophysiological roles through mouse genetic models. Biochimie. 2010;92(6):651-9. https://doi. org/10.1016/j.biochi.2010.02.007.

31. Montrose DC, Nakanishi M, Murphy RC, Zarini S, McAleer JP, Vella AT, et al. The role of PGE2 in intestinal inflammation and tumorigenesis. Prostaglandins Other Lipid Mediat. 2015;116-117:26-36. https://doi.org/10.1 016/j.prostaglandins.2014.10.002.

32. Wirtz S, Popp V, Kindermann M, Gerlach K, Weigmann B, Fichtner-Feigl S, et al. Chemically induced mouse models of acute and chronic intestinal inflammation. Nat Protoc. 2017;12(7):1295-309. https://doi.org/10.1038/ nprot.2017.044.

33. Hamamoto N, Maemura K, Hirata I, Murano M, Sasaki S, Katsu K. Inhibition of dextran sulphate sodium (DSS)-induced colitis in mice by intracolonically administered antibodies against adhesion molecules (endothelial leucocyte adhesion molecule-1 (ELAM-1) or intercellular adhesion molecule-1 (ICAM1)). Clin Exp Immunol. 1999;117(3):462-8. https://doi.org/10.1046/j.1365-224 9.1999.00985.x.

34. Cooper HS, Murthy SN, Shah RS, Sedergran DJ. Clinicopathologic study of dextran sulfate sodium experimental murine colitis. Lab Invest. 1993;69(2): 238-49.

35. Vijay-Kumar M, Sanders CJ, Taylor RT, Kumar A, Aitken JD, Sitaraman SV, et al. Deletion of TLR5 results in spontaneous colitis in mice. J Clin Invest. 2007;117(12):3909-21. https://doi.org/10.1172/JCl33084. 
36. Ciceri P, Zhang Y, Shaffer AF, Leahy KM, Woerner MB, Smith WG, et al. Pharmacology of celecoxib in rat brain after kainate administration. J Pharmacol Exp Ther. 2002;302(3):846-52. https://doi.org/10.1124/jpet.302.3. 846.

37. Weigmann B, Tubbe I, Seidel D, Nicolaev A, Becker C, Neurath MF. Isolation and subsequent analysis of murine lamina propria mononuclear cells from colonic tissue. Nat Protoc. 2007;2(10):2307-11. https://doi.org/10.1038/ nprot.2007.315.

38. Laky K, Kruisbeek AM. In vivo depletion of T lymphocytes. Curr Protoc Immunol. 2016:113(1). https://doi.org/10.1002/0471142735.im0401s113.

39. Diaz-Granados N, Howe K, Lu J, McKay DM. Dextran sulfate sodium-induced colonic histopathology, but not altered epithelial ion transport, is reduced by inhibition of phosphodiesterase activity. Am J Pathol. 2000;156(6):2169_ 77. https://doi.org/10.1016/S0002-9440(10)65087-0.

40. Turner JR. Intestinal mucosal barrier function in health and disease. Nat Rev Immunol. 2009;9(11):799-809. https://doi.org/10.1038/nri2653.

41. Chan CB, Abe M, Hashimoto N, Hao C, Williams IR, Liu X, et al. Mice lacking asparaginyl endopeptidase develop disorders resembling hemophagocytic syndrome. Proc Natl Acad Sci U S A. 2009;106(2):468-73. https://doi.org/10.1 073/pnas.0809824105.

42. Bauer W, Rauner M, Haase M, Kujawski S, Arabanian LS, Habermann I, et al. Osteomyelosclerosis, anemia and extramedullary hematopoiesis in mice lacking the transcription factor NFATc2. Haematologica. 2011;96(11):1580-8. https://doi.org/10.3324/haematol.2011.042515.

43. Spencer RP, Pearson HA. The spleen as a hematological organ. Semin Nucl Med. 1975;5(1):95-102. https://doi.org/10.1016/s0001-2998(75)80007-9.

44. Kim CH. Homeostatic and pathogenic extramedullary hematopoiesis. Blood Med. 2010;1:13-9. https://doi.org/10.2147/JBM.S7224.

45. Schubert TE, Obermaier F, Ugocsai P, Mannel DN, Echtenacher B, Hofstadter $F$, et al. Murine models of anaemia of inflammation: extramedullary haematopoiesis represents a species specific difference to human anaemia of inflammation that can be eliminated by splenectomy. Int J Immunopathol Pharmacol. 2008;21(3):577-84. https://doi.org/10.1177/0394 63200802100310

46. Ajuebor MN, Singh A, Wallace JL. Cyclooxygenase-2-derived prostaglandin $\mathrm{D}(2)$ is an early anti-inflammatory signal in experimental colitis. Am J Physiol Gastrointest Liver Physiol. 2000;279(1):G238-44. https://doi.org/10.1152/a jpgi.2000.279.1.G238.

47. Bettelli E, Carrier Y, Gao W, Korn T, Strom TB, Oukka M, et al. Reciprocal developmental pathways for the generation of pathogenic effector $\mathrm{TH} 17$ and regulatory T cells. Nature. 2006;441(7090):235-8. https://doi.org/10.1038/ nature04753.

48. Chung Y, Chang SH, Martinez GJ, Yang XO, Nurieva R, Kang HS, et al. Critical regulation of early Th17 cell differentiation by interleukin-1 signaling. Immunity. 2009;30(4):576-87. https://doi.org/10.1016/j.immuni.2009.02.007.

49. Veldhoen M, Hocking RJ, Atkins CJ, Locksley RM, Stockinger B. TGFbeta in the context of an inflammatory cytokine milieu supports de novo differentiation of IL-17-producing T cells. Immunity. 2006;24(2):179-89. https://doi.org/10.1016/j.immuni.2006.01.001.

50. Wilson NJ, Boniface K, Chan JR, McKenzie BS, Blumenschein WM, Mattson JD, et al. Development, cytokine profile and function of human interleukin 17-producing helper T cells. Nat Immunol. 2007;8(9):950-7. https://doi.org/1 $0.1038 /$ ni1497.

51. Hsieh CS, Macatonia SE, Tripp CS, Wolf SF, O'Garra A, Murphy KM. Development of $\mathrm{TH} 1 \mathrm{CD}^{+} \mathrm{T}$ cells through IL-12 produced by Listeriainduced macrophages. Science. 1993;260(5107):547-9. https://doi.org/10.112 6/science.8097338

52. Morteau O, Morham SG, Sellon R, Dieleman LA, Langenbach R, Smithies O, et al. Impaired mucosal defense to acute colonic injury in mice lacking cyclooxygenase-1 or cyclooxygenase-2. J Clin Invest. 2000;105(4):469-78. https://doi.org/10.1172/JCl6899.

53. Tanaka K, Suemasu S, Ishihara T, Tasaka Y, Arai Y, Mizushima T. Inhibition of both COX-1 and COX-2 and resulting decrease in the level of prostaglandins E2 is responsible for non-steroidal anti-inflammatory drug (NSAID)-dependent exacerbation of colitis. Eur J Pharmacol. 2009;603(1-3): 120-32. https://doi.org/10.1016/j.ejphar.2008.11.058.

54. Sann H, Erichsen J, Hessmann M, Pahl A, Hoffmeyer A. Efficacy of drugs used in the treatment of IBD and combinations thereof in acute DSSinduced colitis in mice. Life Sci. 2013;92(12):708-18. https://doi.org/10.1016/j. Ifs. 2013.01 .028
55. Watanabe Y, Murata T, Amakawa M, Miyake Y, Handa T, Konishi K, et al. KAG-308, a newly-identified EP4-selective agonist shows efficacy for treating ulcerative colitis and can bring about lower risk of colorectal carcinogenesis by oral administration. Eur J Pharmacol. 2015;754:179-89. https://doi.org/1 0.1016/j.ejphar.2015.02.021.

56. Trebino CE, Eskra JD, Wachtmann TS, Perez JR, Carty TJ, Audoly LP. Redirection of eicosanoid metabolism in MPGES-1-deficient macrophages. J Biol Chem. 2005; doi:M412075200 [pii];280(17):16579-85. https://doi.org/10.1 074/jbc.M412075200.

57. Boulet $L$, Ouellet M, Bateman KP, Ethier D, Percival MD, Riendeau D, et al. Deletion of microsomal prostaglandin E2 (PGE2) synthase-1 reduces inducible and basal PGE2 production and alters the gastric prostanoid profile. J Biol Chem. 2004;279(22):23229-37. https://doi.org/10.1074/jbc.M4 00443200 M400443200 [pii].

58. Monrad SU, Kojima F, Kapoor M, Kuan EL, Sarkar S, Randolph GJ, et al. Genetic deletion of MPGES-1 abolishes PGE2 production in murine dendritic cells and alters the cytokine profile, but does not affect maturation or migration. Prostaglandins Leukot Essent Fatty Acids. 2011;84(3-4):113-21. https://doi.org/10.1016/j.plefa.2010.10.003.

59. Hokari R, Kurihara C, Nagata N, Aritake K, Okada Y, Watanabe C, et al. Increased expression of lipocalin-type-prostaglandin D synthase in ulcerative colitis and exacerbating role in murine colitis. Am J Physiol Gastrointest Liver Physiol. 2011;300(3):G401-8. https://doi.org/10.1152/ajpgi.00351.2010.

60. Iwanaga K, Nakamura T, Maeda S, Aritake K, Hori M, Urade Y, et al. Mast cellderived prostaglandin D2 inhibits colitis and colitis-associated colon cancer in mice. Cancer Res. 2014;74(11):3011-9. https://doi.org/10.1158/0008-5472. CAN-13-2792.

61. Tessner TG, Cohn SM, Schloemann S, Stenson WF. Prostaglandins prevent decreased epithelial cell proliferation associated with dextran sodium sulfate injury in mice. Gastroenterology. 1998;115(4):874-82. https://doi.org/10.101 6/s0016-5085(98)70259-8.

62. Fukata M, Chen A, Klepper A, Krishnareddy S, Vamadevan AS, Thomas LS, et al. Cox-2 is regulated by Toll-like receptor-4 (TLR4) signaling: role in proliferation and apoptosis in the intestine. Gastroenterology. 2006;131(3): 862-77. https://doi.org/10.1053/j.gastro.2006.06.017.

63. Singer II, Kawka DW, Schloemann S, Tessner T, Riehl T, Stenson WF. Cyclooxygenase 2 is induced in colonic epithelial cells in inflammatory bowel disease. Gastroenterology. 1998;115(2):297-306. https://doi.org/10.101 6/s0016-5085(98)70196-9.

64. Ishikawa TO, Oshima M, Herschman HR. Cox-2 deletion in myeloid and endothelial cells, but not in epithelial cells, exacerbates murine colitis. Carcinogenesis. 2011;32(3):417-26. https://doi.org/10.1093/carcin/bgq268.

65. Maseda D, Banerjee A, Johnson EM, Washington MK, Kim H, Lau KS, et al. mPGES-1-mediated production of PGE2 and EP4 receptor sensing regulate T cell colonic inflammation. Front Immunol. 2018;9:2954. https://doi.org/1 0.3389/fimmu.2018.02954.

66. Nakanishi M, Perret C, Meuillet EJ, Rosenberg DW. Non-cell autonomous effects of targeting inducible PGE2 synthesis during inflammationassociated colon carcinogenesis. Carcinogenesis. 2015;36(4):478-86. https:// doi.org/10.1093/carcin/bgv004.

67. Egger B, Bajaj-Elliott M, MacDonald TT, Inglin R, Eysselein VE, Buchler MW Characterisation of acute murine dextran sodium sulphate colitis: cytokine profile and dose dependency. Digestion. 2000;62(4):240-8. https://doi.org/1 $0.1159 / 000007822$

68. Ito R, Shin-Ya M, Kishida T, Urano A, Takada R, Sakagami J, et al. Interferongamma is causatively involved in experimental inflammatory bowel disease in mice. Clin Exp Immunol. 2006;146(2):330-8. https://doi.org/10.1111/j.13 65-2249.2006.03214.x

69. Ito R, Kita M, Shin-Ya M, Kishida T, Urano A, Takada R, et al. Involvement of IL-17A in the pathogenesis of DSS-induced colitis in mice. Biochem Biophys Res Commun. 2008;377(1):12-6. https://doi.org/10.1016/j.bbrc.2008.09.019.

70. Globig AM, Hennecke N, Martin B, Seidl M, Ruf G, Hasselblatt P, et al. Comprehensive intestinal $T$ helper cell profiling reveals specific accumulation of IFN-gamma ${ }^{+} \mathrm{L}-17^{+}$coproducing $\mathrm{CD}^{+} \mathrm{T}$ cells in active inflammatory bowel disease. Inflamm Bowel Dis. 2014;20(12):2321-9. https:// doi.org/10.1097/MIB.0000000000000210.

71. Barrie A, Khare A, Henkel M, Zhang Y, Barmada MM, Duerr R, et al. Prostaglandin E2 and IL-23 plus IL-1beta differentially regulate the Th1/Th17 immune response of human CD161(+) CD4(+) memory T cells. Clin Transl Sci. 2011;4(4):268-73. https://doi.org/10.1111/j.1752-8062.2011.00300.x. 
72. Yao C, Sakata D, Esaki Y, Li Y, Matsuoka T, Kuroiwa K, et al. Prostaglandin E2EP4 signaling promotes immune inflammation through Th1 cell differentiation and Th17 cell expansion. Nat Med. 2009;15(6):633-40. https:// doi.org/10.1038/nm.1968.

73. Araki Y, Mukaisho K, Sugihara H, Fujiyama Y, Hattori T. Proteus mirabilis sp. intestinal microflora grow in a dextran sulfate sodium-rich environment. Int J Mol Med. 2010;25(2):203-8.

74. Bamba S, Andoh A, Ban H, Imaeda H, Aomatsu T, Kobori A, et al. The severity of dextran sodium sulfate-induced colitis can differ between dextran sodium sulfate preparations of the same molecular weight range. Dig Dis Sci. 2012;57(2):327-34. https://doi.org/10.1007/s10620-011-1881-X.

75. Sun X, He S, Lv C, Sun X, Wang J, Zheng W, et al. Analysis of murine and human Treg subsets in inflammatory bowel disease. Mol Med Rep. 2017; 16(3):2893-8. https://doi.org/10.3892/mmr.2017.6912.

76. Sakaguchi S, Sakaguchi N, Asano M, Itoh M, Toda M. Immunologic selftolerance maintained by activated T cells expressing IL-2 receptor alphachains (CD25). Breakdown of a single mechanism of self-tolerance causes various autoimmune diseases. J Immunol. 1995;155:1151-64.

77. Mottet C, Uhlig HH, Powrie F. Cutting edge: cure of colitis by CD4+CD25+ regulatory T cells. J Immunol. 2003;170(8):3939-43. https://doi.org/10.4049/ jimmunol.170.8.3939.

78. Maul J, Loddenkemper C, Mundt P, Berg E, Giese T, Stallmach A, et al. Peripheral and intestinal regulatory $\mathrm{CD} 4^{+} \mathrm{CD} 25$ (high) T cells in inflammatory bowel disease. Gastroenterology. 2005;128(7):1868-78. https://doi.org/10.1 053/j.gastro.2005.03.043.

79. Yu QT, Saruta M, Avanesyan A, Fleshner PR, Banham AH, Papadakis KA Expression and functional characterization of $\mathrm{FOXP3}^{+} \mathrm{CD}^{+}$regulatory $\mathrm{T}$ cells in ulcerative colitis. Inflamm Bowel Dis. 2007;13(2):191-9. https://doi. org/10.1002/ibd.20053.

80. Saruta M, Yu QT, Fleshner PR, Mantel PY, Schmidt-Weber CB, Banham AH, et al. Characterization of FOXP3 $3^{+} \mathrm{CD}^{+}$regulatory T cells in Crohn's disease. Clin Immunol. 2007;125(3):281-90. https://doi.org/10.1016/j.clim.2007.08.003.

81. Mahic M, Yaqub S, Johansson CC, Tasken K, Aandahl EM. FOXP $3^{+} \mathrm{CD}^{+} \mathrm{CD} 25^{+}$adaptive regulatory $T$ cells express cyclooxygenase- 2 and suppress effector T cells by a prostaglandin E2-dependent mechanism. J Immunol. 2006;177(1):246-54. https://doi.org/10.4049/jimmunol.177.1.246.

82. Chinen T, Komai K, Muto G, Morita R, Inoue N, Yoshida H, et al. Prostaglandin E2 and SOCS1 have a role in intestinal immune tolerance. Nat Commun. 2011;2(1):190. https://doi.org/10.1038/ncomms1181.

83. Axelsson LG, Landstrom E, Goldschmidt TJ, Gronberg A, Bylund-Fellenius AC. Dextran sulfate sodium (DSS) induced experimental colitis in immunodeficient mice: effects in CD4(+)-cell depleted, athymic and NK-cell depleted SCID mice. Inflamm Res. 1996;45(4):181-91. https://doi.org/10.1 007/BF02285159.

84. Shintani N, Nakajima T, Okamoto T, Kondo T, Nakamura N, Mayumi T. Involvement of $\mathrm{CD}^{+} \mathrm{T}$ cells in the development of dextran sulfate sodiuminduced experimental colitis and suppressive effect of lgG on their action. Gen Pharmacol. 1998;31(3):477-81. https://doi.org/10.1016/s0306-3623 (98)00004-4.

85. Yamane $H$, Sugimoto $Y$, Tanaka S, Ichikawa A. Prostaglandin E(2) receptors, EP2 and EP4, differentially modulate TNF-alpha and IL-6 production induced by lipopolysaccharide in mouse peritoneal neutrophils. Biochem Biophys Res Commun. 2000;278(1):224-8. https://doi.org/10.1006/bbrc.2000.3779.

86. Akaogi J, Yamada H, Kuroda Y, Nacionales DC, Reeves WH, Satoh M. Prostaglandin E2 receptors EP2 and EP4 are up-regulated in peritoneal macrophages and joints of pristane-treated mice and modulate TNF-alpha and IL-6 production. J Leukoc Biol. 2004;76(1):227-36. https://doi.org/10.11 89/jlb.1203627.

\section{Publisher's Note}

Springer Nature remains neutral with regard to jurisdictional claims in published maps and institutional affiliations.

Ready to submit your research? Choose BMC and benefit from:

- fast, convenient online submission

- thorough peer review by experienced researchers in your field

- rapid publication on acceptance

- support for research data, including large and complex data types

- gold Open Access which fosters wider collaboration and increased citations

- maximum visibility for your research: over $100 \mathrm{M}$ website views per year

At BMC, research is always in progress.

Learn more biomedcentral.com/submissions 